\title{
Recomendações no manejo das complicações infecciosas no transplante de células-tronco hematopoéticas
}

\section{Management of infectious complications after hematopoietic stem cell transplant}

\author{
Marcia Garnica ${ }^{I}$ \\ Clarisse Machado ${ }^{2}$ \\ Paola Cappellano ${ }^{3}$ \\ Viviane V. H. Carvalho \\ Andrea Nicolato 5 \\ Clovis A. Cunha \\ Marcio Nucci ${ }^{6}$
}

\begin{abstract}
A infecção em receptores de transplante de células-tronco hematopoéticas (TCTH) está relacionada a altas taxas de morbidade e mortalidade. O tipo de transplante, a fonte de célula-tronco hematopoética, a utilização de doadores alternativos e outras medidas relacionadas ao procedimento influenciam diretamente no tipo e na intensidade da imunossupressão, modificando o risco de desenvolver uma infecção. Nesta seção são discutidas as estratégias para monitorização, diagnóstico e tratamento das infecções em receptores de TCTH em três fases: na fase pré-transplante, durante a fase de neutropenia, e na fase pós-pega do enxerto. Rev. Bras. Hematol. Hemoter. 2010;32(Supl. 1):140-162.
\end{abstract}

Palavras-chave: Transplante de células-tronco hematopoéticas; neutropenia; infecção; complicações.

\section{Introdução}

A infecção em receptores de transplante de célulastronco hematopoéticas (TCTH) está relacionada a altas taxas de morbidade e mortalidade. A utilização de doadores alternativos, novos imunossupressores e outras medidas relacionadas ao procedimento influenciam diretamente no tipo e na intensidade da imunossupressão, modificando o risco de desenvolver uma infecção. ${ }^{1,2}$

A epidemiologia e o manejo das infecções em receptores de TCTH é um tópico dinâmico e deverá ser avaliada com base nos conhecimentos atuais, epidemiologia de cada centro e na característica individual de cada paciente.

A seguir estão recomendações gerais referentes à prevenção e manejo das infecções, abordadas em três tempos: fase pré-transplante, fase I (entre o condicionamento e a recuperação de neutrófilos) e a fase II ou pós-pega.

\section{Avaliação pré-transplante}

A avaliação pré-transplante engloba uma série de procedimentos que visam à segurança na realização do transplante propriamente dito. Infecções pregressas ou persistentes devem ser investigadas no período pré-transplante através da detecção laboratorial e pela história clínica do paciente e de seu doador no caso de transplante alogênico. A avaliação do estado imunológico do receptor e do doador ajuda a definir o risco de reativação destas infecções após o transplante, assim como o risco de infecção primária, permitindo a implementação de estratégias preventivas.

${ }^{1}$ Infectologista. Universidade Federal do Rio de Janeiro - UFRJ - Rio de Janeiro-RJ.

${ }^{2}$ Infectologista. Universidade de São Paulo - USP / Hospital Amaral Caravalho - São Paulo-SP.

${ }^{3}$ Infectologista. Universidade do Estado de São Paulo - Unifesp - São Paulo-SP.

${ }^{4}$ Infectologista. Universidade Federal do Paraná - UFPR - Curitiba-PR.

${ }^{5}$ Hematologista. Universidade Federal de Juiz de Fora - UFJF - Juiz de Fora-MG.

${ }^{6}$ Hematologista. Universidade Federal do Rio de Janeiro - UFRJ - Rio de Janeiro-RJ.

Faculdade de Medicina da Universidade de São Paulo, FM USP - São Paulo-SP.

Correspondência: Marcio Nucci

Rua Professor Rodolpho Rocco, 255

Universidade Federal do Rio de Janeiro - Cidade Universitária - Ilha do Fundão

21941-617 - Rio de Janeiro-RJ - Brasil

E-mail:mnucci@hucff.ufrj.br

Doi: 10.1590/S1516-84842010005000026 
Da mesma forma, a ocorrência de doenças documentadas antes do transplante pode auxiliar na definição de condutas, tais como vigilância ou profilaxia secundária pós- transplante.

Em algumas situações, o transplante poderá ser adiado temporariamente, ou mesmo contraindicado nesta fase de avaliação.

\section{Avaliação do doador}

A avaliação do doador começa com acesso à história médica, anamnese e exame físico. Estes procedimentos visam coletar informações sobre histórico de infecções prévias e atuais, passagem ou residência por áreas onde há prevalência significativa de doenças infecciosas endêmicas, além de outros dados relevantes. Esta análise deve ser complementada com testes laboratoriais de screening que incluem principalmente aqueles realizados em rotinas de bancos de sangue..$^{3-5}$

As sorologias essenciais incluem infecção causada pelo HIV, hepatite B, hepatite C e HLTV I e II. 3,4,6,7 Sorologias complementares incluem investigação para CMV (citomegalovírus), EBV (Epstein Bar Vírus), sífilis e toxoplasmose..$^{8-11}$

Indivíduos que apresentam infecção aguda para CMV ou EBV não devem ser doadores, assim como aqueles com toxoplasmose aguda, até que a doença tenha sido resolvida. Uma atenção especial deve ser dada nos casos de doadores soropositivos e assintomáticos para Toxoplasma gondii, pelo potencial de transmissão através do transplante. ${ }^{12}$ Em relação à doença de Chagas, considerando que o Brasil é uma área com ampla distribuição desta doença, os potenciais doadores devem ser submetidos a um teste de screening sorológico, mesmo porque a transmissão desta doença por transfusão sanguínea está bem documentada. , $^{8,13}$ Alguns autores recomendam suspender a doação de células-tronco hematopoéticas se existe história passada desta infecção, pois o parasita pode persistir, a despeito da terapia. ${ }^{3,15,16}$

Doadores com sintomas de tuberculose ativa não devem doar até a doença estar controlada após terapia medicamentosa apropriada. Entretanto, não há evidência de risco adicional se o teste tuberculínico de pele for positivo e o indivíduo for assintomático. A realização de PPD de rotina não é necessária. ${ }^{17,18}$

Os doadores provenientes de regiões endêmicas para malária devem ser interrogados sobre história ativa ou pregressa da doença e devem, no mínimo, ter um esfregaço sanguíneo coletado (BIII). Alguns autores recomendam tratamento empírico para todos os doadores com história de malária, independente do resultado do esfregaço sanguíneo. ${ }^{19}$

Em situações nas quais o doador é recém-nato $(<01$ mês de vida), a mãe deverá ser submetida aos exames de screening. ${ }^{4,7}$

O tempo entre a coleta dos exames de screening e a doação não deve passar de sete dias no caso de doadores de linfócitos e sangue de cordão umbilical e de trinta dias no caso de doadores de célula-tronco de sangue periférico e medula óssea, de acordo com a política adotada nos EUA.

\section{Avaliação do receptor}

A avaliação pré-transplante de um paciente candidato a receber células-tronco hematopoéticas, no que diz respeito ao item infecção, também inclui história médica, anamnese, exame físico e exames laboratoriais. O objetivo desta análise inclui tanto o conhecimento do risco de ocorrência de infecção durante a fase pós-transplante quanto a adoção de medidas preventivas cabíveis em cada situação.

Sempre que possível, o transplante deve ser evitado se o produto de célula hematopoética for infectado, porém, se as circunstâncias obrigam por falta de opção de outro doador, deve-se avaliar cada caso separadamente e, se a melhor opção ainda for realizar o transplante, é recomendado que o receptor seja informado de que o procedimento poderá transmitir agentes infecciosos, assinando um termo de consentimento autorizando sua realização.

Os exames laboratoriais de screening realizados no prétransplante para o receptor também incluem aqueles coletados de rotina em bancos de sangue, como HIV, hepatite B, hepatite C e HLTV I e II, além de investigação sobre status sorológico de infecção por CMV, EBV, sífilis e toxoplasmose. , $^{3,46-11}$ Adicionalmente ao doador, a avaliação laboratorial do receptor pode também incluir sorologia para o vírus herpes simplex $\mathrm{e}$ Varicela zoster. Abaixo, seguem as recomendações para cada agente específico.

\section{Citomegalovírus (CMV)}

Os candidatos devem ser submetidos à dosagem sérica de IgG para CMV antes do transplante para determinar o risco para infecção primária por este vírus ou reativação após o transplante (AII). ${ }^{20}$

Recomendação:

- Receptores de TCTH alogênico soronegativos para o CMV com doadores também soronegativos devem receber transfusões de sangue e derivados com filtro de leucócitos ou de doadores de banco de sangue negativos para o CMV, para diminuir o risco de infecção primária pelo CMV pós$\mathrm{TCTH}^{21}(\mathrm{AI})$.

- No caso de uso de filtros, os produtos preparados devem conter menos de $1 \times 10^{6}$ leucócitos residuais por unidade $^{21}(\mathrm{AI})$.

- No caso de receptores de TCTH autólogos soronegativos para o CMV que receberam tratamento prévio com fludarabina ou alemtuzumab, recomenda-se que a mesma estratégia descrita acima seja adotada (BII).

- Receptores de TCTH alogênico não aparentado ou aparentado com mismatch, soropositivos para o CMV, devem preferencialmente receber transplante de células-tronco hematopoéticas a partir de doadores também soropositivos $(\mathrm{BII}){ }^{22}$ 
- Investigar história de doença documentada pelo CMV antes do transplante, uma vez que estes pacientes têm risco aumentado de doença precoce por CMV e óbito pós$\mathrm{TCTH}(\mathrm{BIII}) .^{20}$

\section{Epstein Bar vírus (EBV)}

Os candidatos a receptores devem ter dosado o $\mathrm{IgG}$ sérico para EBV a fim de determinar risco de doença primária após o transplante. Nos receptores de transplante, a síndrome clínica mais importante associada à replicação do EBV é a doença linfoproliferativa pós-transplante (PTLD), com altas taxas de mortalidade. ${ }^{23-26}$

Os fatores de risco para reativação do EBV e desenvolvimento de doença linfoproliferativa pós-transplante (DLPT) são: idade menor, receptor soronegativo com doador soropositivo, transplantes não aparentados ou com disparidade de HLA, e uso de ATG ou depleção de células T. Desta forma, recomenda-se:

- Pesquisa de anticorpos específicos para o EBV em receptores e doadores para avaliar o risco de infecção primária pelo EBV pós-TCTH (BII). A recomendação é ainda mais importante em população pediátrica (AII). ${ }^{27}$

- Receptores de TCTH soronegativos para o EBV apresentam risco maior de desenvolver doença linfoproliferativa pós-transplante se o doador for soropositivo. Havendo possibilidade, doador soronegativo deve ser selecionado para receptor que seja soronegativo para o EBV, já que o vírus pode ser transmitido pelo enxerto (BII).

- Os doadores devem fazer sorologia antes do transplante, especialmente nos transplantes não aparentados ou aparentados com disparidade de HLA, ou ainda quando se planeja um transplante com uso de ATG ou com depleção de células T (AII).

\section{Virus herpes simples (HSV)}

Todos os candidatos a receptor devem realizar dosagem de IgG para HSV antes do transplante (AII), e, no caso de sorologia positiva em transplante alogênico, o aciclovir profilático está recomendado (AI). No entanto, em situações populacionais conhecidas, em que a sorologia positiva para o vírus da herpes é a realidade predominante, a estratégia de recomendar o aciclovir profilático para todos os receptores sem a realização do exame de sorologia pode ser estudada economicamente..$^{25}$

Recomendações:

- No Brasil, a soroprevalência do HSV em população adulta é alta. Portanto, não se recomenda a triagem sorológica em receptores de TCTH adultos (custo maior que o benefício).

- A pesquisa de anticorpos anti-HSV pré-transplante se justifica e é recomendada na população pediátrica (menores de 15 anos) (AIII).

- Não é necessário fazer sorologia do doador (AIII).

- Recomenda-se investigar história pregressa de herpes genital de repetição para orientar extensão da profilaxia de HSV no período pós-pega (BIII).

Virus varicela zoster (VZV)

Receptores de TCTH alogênico e autólogo têm risco de $20 \%$ a $50 \%$ de desenvolver herpes zoster, geralmente ocorrendo entre o $3^{\circ}$ e o $12^{\circ}$ mês pós-TCTH. O risco é maior nos transplantes não aparentados, aparentados com mismatch ou em pacientes recebendo tratamento para a doença do enxerto contra o hospedeiro $(\mathrm{DECH})$. As sequelas e complicações do zoster também são maiores nestes pacientes.

- História pregressa de varicela ou herpes zoster deve ser investigada em todos os receptores de TCTH. Havendo informação consistente, não há necessidade de realização de sorologia no pré-transplante, uma vez que, em geral, há concordância entre história e presença de anticorpos anti$\mathrm{VZV} \cdot{ }^{28} \mathrm{Na}$ ausência de informação, a sorologia do receptor deve ser realizada (AII).

- Pacientes soronegativos para o VZV devem ser orientados para evitar exposição a pessoas com varicela ou herpes zoster (AII). ${ }^{29}$

- No caso de sorologia positiva, a profilaxia com aciclovir está rotineiramente recomendada no primeiro ano de pós-transplante alogênico (BI). ${ }^{25,30,31}$

\section{Vírus da hepatite A (HAV)}

A dosagem sérica de IgG para hepatite A em doadores e receptores não está formalmente recomendada, uma vez que a sua positividade na ausência de IgM indica exposição remota e não tem impacto na evolução do transplante de células-tronco (DIII). Entretanto, a dosagem de IgM está indicada na investigação daqueles pacientes com hepatite aguda (AII). Se o teste for positivo no receptor, o transplante deve ser atrasado pelo risco maior de síndrome de obstrução sinusoidal, que segue a toxicidade hepática dos regimes mieloablativos (DII). Se o teste for positivo no doador, o transplante também deve ser adiado pelo risco de transmissão e aumento da morbidade e mortalidade (EII).

\section{Virus da hepatite $B(H B V)$}

No Brasil, a infecção pelo vírus da hepatite B é endêmica e a soroprevalência varia de região para região. As recomendações estão a seguir: ${ }^{32,33}$

- Realizar dosagem sorológica para o vírus da hepatite B é mandatória para prevenir exposição e doença. A análise deve incluir HBsAg, Anti-HBs, Anti-HBc (AII). ${ }^{34}$

- No caso de receptor soronegativo, um doador também soronegativo deve ser selecionado. Entretanto, não é contraindicado o uso de doador HBsAg positivo caso não exista outro doador compatível, uma vez que o risco de transmissão é menor que 30\% (BIII). ${ }^{35}$

- Para todos os pacientes com anti-HBc e Anti-HBs positivos deve ser solicitada a carga viral (HBV-DNA) (AII). 
- No caso de doador HBsAg positivo, recomenda-se o tratamento do doador (após informação dos riscos e consentimento) com lamivudina ou entecavir por, pelo menos, quatro semanas, ou até negativação do HBsAg ou da carga viral (HBV-DNA) (CIII).

- O receptor deve ser monitorizado até seis meses após o transplante através dos níveis de transaminases e de marcadores sorológicos e/ou detecção de HBV-DNA. No caso de positivação dos marcadores de replicação viral, o paciente deve receber tratamento (AIII).

- No caso de doador anti-HBc positivo, deve ser feita a detecção de HBV-DNA por PCR. Se positivo, tratar o doador, e se a PCR for negativa, o transplante pode ser realizado sem demais precauções.

- Se o receptor for anti-HBc positivo, deve ser selecionado um doador que também tenha imunidade natural (anti$\mathrm{HBc}$ e anti-HBs positivos), que possa ser transferida ao receptor.

\section{Virus da hepatite $\mathrm{C}(\mathrm{HCV})$}

Todos os candidatos a transplante devem passar por uma avaliação do risco de hepatite $\mathrm{C}$ através de uma adequada história médica, exame físico e dosagem de anti-HCV (AII) e ALT sérica (BIII). Embora a infecção pelo HCV não altere a morbidade ou a mortalidade dos receptores nos primeiros anos pós-TCTH, o tempo de evolução para cirrose hepática é mais curto do que em pacientes não transplantados. ${ }^{35,36}$

- Sorologia para o HCV é recomendada tanto para todos os candidatos a TCTH como para os doadores (AII).

- Além da sorologia, recomenda-se história clínica detalhada, exame físico cuidadoso e dosagem sérica de ALT para melhor avaliação do risco de hepatite $\mathrm{C}$.

- PCR para HCV (HCV-RNA) está recomendado em pacientes e doadores com sorologia negativa, mas com história sugestiva de risco (transfusão de sangue antes de 1993, usuário de drogas, tatuagem, etc) ou que tenham ALT inexplicavelmente aumentada (AII). ${ }^{37}$

- Doadores anti-HCV positivos devem ser avaliados clínicamente para excluir doença crônica que pode aumentar o risco cirúrgico e contraindicar a doação de medula óssea (EIII).

- Doadores HCV-RNA positivos invariavelmente transmitem a infecção para o receptor. Por outro lado, o risco é mínimo se a carga viral for negativa por ocasião da doação. ${ }^{38}$ Para diminuir a carga viral de $\mathrm{HCV}$ do doador e minimizar o risco de transmissão, pode ser tentado o tratamento do doador (após informação dos riscos e consentimento) com a associação padrão de antivirais (ribavirina e interferon) (BIII). ${ }^{39}$

- Pacientes infectados pelo HCV e que necessitam de um transplante de células hematopoéticas podem recebê-lo de um doador $\mathrm{HCV}$ positivo desde que não exista um doador alternativo e o paciente esteja ciente dos riscos potenciais de complicações a longo prazo (BIII). ${ }^{40}$ Biópsia hepática está indicada nestes candidatos nas seguintes situações: sobrecarga de ferro, história de ingestão aumentada de álcool, história de hepatite há mais de 10 anos e evidência clínica de doença hepática crônica (AIII).

- Se a biópsia revelar cirrose ou fibrose hepática, o condicionamento mieloablativo não deve incluir ciclofosfamida ou TBI $\geq 12 \mathrm{GY}$, uma vez que estes regimes aumentam em quase dez vezes o risco de síndrome de obstrução sinusoidal fatal nesta população. $\mathrm{O}$ doador com doença hepática crônica ou qualquer outra manifestação do HCV extra-hepática deve ter sua doação contraindicada (EIII).

\section{Mycobacterium tuberculosis (TB)}

Especialistas recomendam avaliação para TB latente ou ativa em pacientes candidatos a TCTH (BII). Esta avaliação deve incluir história anterior de TB ativa, exposição prévia e resultados anteriores de PPD. Não há consenso sobre o benefício de solicitar rotineiramente o exame de PPD.

Qualquer paciente com uma história recente de PPD positivo deve investigar TB ativa. No mínimo, o paciente deve ser interrogado sobre sintomas como tosse e dispneia e um RX de tórax deve ser solicitado (AII) ${ }^{41}$ Se a doença ativa for detectada, o tratamento adequado deve ser iniciado e o transplante deve ser adiado até que a infecção ativa esteja controlada. Porém, se o PPD for positivo sem TB ativa, o paciente deve iniciar tratamento para TB latente, com isoniazida, e o transplante não precisa ser adiado.

\section{Toxoplasma gondii}

Devido ao fato da maioria das ocorrências de toxoplasmose em receptores de transplante de células hematopoéticas ser causada por reativação, os candidatos a transplante alogênico devem dosar IgG a fim de determinar se apresentam risco de reativação após o procedimento (BIII). ${ }^{42}$ A incidência de doença pelo $T$. gondii varia de acordo com a soroprevalência geográfica. Reativação clínica ocorre em $2 \%$ a $6 \%$ daqueles soropositivos antes do transplante. ${ }^{42-45}$

\section{Strongyloides stercoralis}

Documentação de estrongiloidíase em pacientes imunossuprimidos e transplantados no Brasil está ao redor de $13 \%$ a $20 \%{ }^{46,47}$ No entanto, estudos brasileiros indicaram que terapia profilática nestes pacientes não está recomendada, pela baixa incidência de doença disseminada e pelos efeitos adversos da terapia. ${ }^{48,49}$ Os candidatos com eosinofilia não explicada ou que residem ou viajaram para áreas endêmicas para estrongiloidíase devem ser investigados para doença assintomática (BIII) e receber tratamento empírico antes do transplante (BIII). ${ }^{50}$

\section{Trypanosoma cruzi}

Os candidatos a transplante e sob risco para infecção para T. cruzi devem dosar IgG para este agente (BIII) ${ }^{51} \mathrm{~A}$ soropositividade não é uma contraindicação para o trans- 
plante, entretanto, se a doença aguda ocorrer em um receptor soropositivo, particularmente durante a neutropenia, a reativação deve ser incluída no diagnóstico diferencial (BIII). ${ }^{51,52}$ Alguns especialistas têm proposto uso de benzonidazol ou nifurtimox para terapia preemptiva ou profilaxia entre os receptores soropositivos, mas ainda os dados são insuficientes para se estabelecer uma recomendação. ${ }^{37,51,53}$

\section{Malária}

Os receptores provenientes de áreas endêmicas devem ser investigados através de esfregaço sanguíneo, testes rápidos ou PCR para doença ativa, antes do transplante (AIII). Não há evidência suficiente para recomendação de profilaxia em pacientes que vivem em áreas endêmicas.

\section{Manejo de infecção na fase I ou fase neutropênica (até pega)}

A fase I, ou fase pré-pega, consiste no período entre o início do condicionamento e a recuperação de granulócito. Nesta fase, a grande maioria dos pacientes estará em ambiente hospitalar e apresentará como principais fatores de risco para desenvolvimento de infecção a presença de um cateter venoso, mucosite e neutropenia. Nesta fase do transplante, as infecções mais frequentes são as bacterianas, virais e fúngicas. ${ }^{1}$ As medidas de prevenção e controle destas infecções são principalmente relacionadas ao controle do ambiente, às profilaxias e ao uso de terapias empíricas ou específicas.

\section{Controle do ambiente}

Apesar da extensa experiência clínica quanto aos principais fatores de risco para a aquisição de infecções no paciente submetido a transplante de células tronco-hematopoéticas (TCTH), há poucos estudos randomizados e controlados avaliando a eficácia de medidas de prevenção de infecções nestes pacientes. ${ }^{54}$

As recomendações a seguir são baseadas nas diretrizes publicadas, em 2001, pelo Centers for Disease Control and Prevention (CDC) em conjunto com a Infectious Disease Society for America (IDSA) e American Society of Blood and Bone Marrow Transplantation (ASBMT), ${ }^{55}$ atualizadas com as recomendações publicadas por outros órgãos e sociedades. É importante ressaltar que, diante da falta de estudos em pacientes submetidos a TCTH, algumas recomendações são baseadas nos pacientes hospitalizados em geral, além do senso comum no manejo dos pacientes imunossuprimidos. ${ }^{56}$

Medidas rotineiras de controle de infecções também devem ser realizadas nos pacientes submetidos a TCTH, tais como técnica asséptica no cuidado dos catéteres venosos centrais, cuidados com catéteres urinários, feridas, traqueostomias e ventiladores. ${ }^{54}$ No entanto, nestes pacientes, também são necessárias outras medidas, como o controle da qualidade do ar, água, e outras precauções que visam reduzir a exposição do paciente a microorganismos patogênicos. ${ }^{56}$

No Anexo 1 estão listadas as principais recomendações quanto ao controle e prevenção de infecções relacionadas à assistência à saúde nos pacientes submetidos a TCTH.

Medidas de controle de bactérias multirresistentes, legionelose e Clostridium difficile estão abordadas a seguir:

\section{A) Controle de bactérias multirresistentes}

Para o controle de infecções por bactérias multirresistentes, é importante a prevenção da transmissão cruzada de microorganismos; as principais medidas que devem ser enfatizadas são: a higiene das mãos, as precauções de contato, a limpeza do ambiente e o uso racional de antimicrobianos.$^{57}$ No entanto, a principal medida para redução de transmissão cruzada é a promoção e melhoria da higiene das mãos. ${ }^{58,59}$

Pacientes com identificação de um microorganismo resistente deverão ficar sob precauções de contato e a limpeza do ambiente deve ser rigorosa. ${ }^{60}$

O emprego de culturas de vigilância deve ser avaliado cuidadosamente quanto aos reais benefícios que essa prática trabalhosa e custosa apresenta. Se não se espera um real benefício com as culturas de vigilância, as mesmas não devem ser feitas.

\section{B) Legionelose}

Medidas que devem ser consideradas para prevenir as infecções por Legionella ssp incluem evitar que a água do hospital fique estagnada, principalmente a água quente, e evitar a aerosolização da água. ${ }^{54}$

Culturas periódicas da água podem ser realizadas nos centros de transplante, porém não há normatização quanto à frequência que estas culturas devam ser realizadas. ${ }^{55}$

A vigilância também pode ser feita a partir de dados epidemiológicos; caso se confirme um caso de legionelose hospitalar, o sistema de água deve ser avaliado. É fundamental manter um alto grau de suspeita diagnóstica para legionelose e utilizar testes diagnósticos em pacientes com pneumonia hospitalar. ${ }^{61}$

Caso a água esteja contaminada, deve-se evitar qualquer contato de pacientes em risco e promover a limpeza do reservatório de água. ${ }^{55}$

\section{C) Clostridium difficile}

Além das precauções de contato instituídas durante a infecção, a higiene das mãos, a limpeza ambiental com produtos à base de cloro e a redução do uso dos antimicrobianos podem auxiliar no controle da disseminação do Clostridium difficile na unidade. ${ }^{62,63}$

D) O filtro HEPA

É recomendado filtro HEPA com taxa de filtração do ar superior a 12 trocas por hora para pacientes submetidos a 
TCTH alogênico, devido ao risco aumentado de infecções por fungos filamentosos veiculados pelo ar (AIII). Para pacientes submetidos a TCTH autólogo, o ambiente protegido deverá ser considerada em situações muito especiais quando houver expectativa de neutropenia prolongada.

\section{Profilaxias}

Medidas profiláticas são amplamente utilizadas neste primeiro mês após TCTH. Estas medidas têm como objetivo evitar ou diminuir a frequência de infecção graves, como as bacterianas, virais e fúngicas. ${ }^{1}$

Estão descritas abaixo as profilaxias com maior grau de recomendação, no entanto vale ressaltar que, em situações especiais e dependendo da epidemiologia local, deverá ser revista a aplicabilidade destas medidas.

- Profilaxia antibacteriana

A utilização de medidas antimicrobianas com o intuito de redução de infecção bacteriana durante a neutropenia iniciou-se na década de 70, porém esta intervenção foi associada a altas taxas de resistência bacteriana e pouco benefício clínico. No entanto, recentemente, novos estudos demonstraram impacto desta intervenção em reduzir infecções $^{64,65}$ e mortalidade. ${ }^{66,67}$

A recomendação atual para adultos com expectativa de neutropenia maior que sete dias é a utilização de fluoroquinolona (ciprofloxacina $500 \mathrm{mg}$ oral, de 12/12 horas (BII) ou levofloxacina $500 \mathrm{mg}$ oral, uma vez ao dia (BI), a partir do início do condicionamento ou da infusão de células-tronco hematopoéticas até a recuperação de granulócitos, ou o desenvolvimento de febre e início de terapia antimicrobiana empírica. A utilização de moxifloxacina foi associada, em diversos estudos, a um aumento no risco de colite pseudomembranosa, não sendo atualmente sugerida como alternativa. Associação de anti-Gram-positivos, como glicopeptídios, é fortemente desencorajada (DIII) devido à sua associação com emergência de resistência. ${ }^{68}$ Uso de metronidazol profilático como medida de descontaminação do trato gastrintestinal também é fortemente desencorajado (DIII). Uso de antimicrobianos profiláticos esteve associado a aumento na resistência à droga em uso e às demais classes de drogas; assim, é altamente recomendado que se faça uma monitorização permanente de resistência (AI) ${ }^{67}$

\section{- Profilaxia antiviral}

Neste período, são relevantes as reativações das infecções pelo HSV, pelo CMV e as infecções por vírus respiratórios, em especial o vírus respiratório sincicial (RSV).

Cerca de $80 \%$ dos receptores de TCTH soropositivos para o vírus do herpes simplex (HSV) desenvolvem infecção sintomática pelo HSV no primeiro mês pós-transplante, se nenhuma profilaxia for empregada. ${ }^{69,70} \mathrm{O}$ período de maior excreção do HSV coincide com o período da mucosite decorrente do regime de condicionamento, agravando as infecções bacterianas no período de neutropenia.

Com relação ao CMV no período pré-pega, atenção deve ser dada ao receptor de TCTH alogênico com história de doença pelo CMV pré-transplante. ${ }^{20}$

Receptores de TCTH que adquirem infecção de trato respiratório alto pelo RSV antes da enxertia de neutrófilos apresentam maior risco de progressão para pneumonia. ${ }^{71}$

1. Durante o período de neutropenia, a reativação da infecção pelo vírus do herpes simplex deve ser evitada através da profilaxia com antiviral (AI).

2. As profilaxias podem ser feitas com o aciclovir endovenoso $\left(250 \mathrm{mg} / \mathrm{m}^{2}\right.$ ou $5 \mathrm{mg} / \mathrm{kg}$ a cada 12 horas) (AI) ou aciclovir oral (doses de $3 \times 200 \mathrm{mg} /$ dia a $2 \times 800 \mathrm{mg} /$ dia) (AI) ou, ainda, valaciclovir oral $(2 \times 500 \mathrm{mg})^{72}$ (AII) a partir do condicionamento até três a cinco semanas pós-TCTH.

3. Profilaxia oral prolongada pode ser indicada em receptores com história pregressa de herpes genital de repetição (BIII), ou com doença do enxerto contra o hospedeiro $(\mathrm{DECH})$, ou recebendo drogas imunossupressoras incluindo corticosteroides (BII).

4. Não está indicada a rotina de vigilância de HSV por cultivo ou PCR após o TCTH (CIII).

5. Receptor de TCTH alogênico com história de doença pelo CMV pré-transplante deve ser submetido a vigilância do CMV com técnica sensível (PCR) para detecção precoce de reativação, especialmente durante o período de neutropenia, quando os resultados da antigenemia podem se mostrar inconclusivos (BII).

6. Investigação cuidadosa de sintomas respiratórios deve ser feita em todos os candidatos a TCTH no momento da admissão. Na presença de sintomas, amostras de lavado nasal ou aspirado de nasofaringe devem ser tomadas para pesquisa de RSV por imunofluorescência direta ou PCR (BII).

7. No caso de diagnóstico de RSV, o condicionamento e o TCTH devem ser adiados (se possível) 73 $^{73}$ (BII). Para evitar a dispersão de RSV no ambiente hospitalar, o paciente deverá receber alta até sua recuperação, ou ser retirado de unidade de TCTH que tenha quartos com pressão positiva (BIII), e colocado sob isolamento de contato.

8. Menos de $4 \%$ das amostras são positivas em pacientes sem sintomas respiratórios. Desta forma, a coleta de amostras (screening) pré-admissão para diagnóstico de vírus respiratórios fica a critério do centro transplantador (CII).

- Profilaxia antifúngica

A fase pré-pega, ou neutropênica, é marcada por um risco alto de desenvolvimento de infecções fúngicas invasivas por Candida ou por fungos filamentosos. A infecção invasiva por Candida apresenta, como fatores de risco, neutropenia, mucosite e a presença de cateter venoso central. Este tipo de infecção pode ocorrer no TCTH autólogo e também no alogênico. No entanto, infecções por fungos filamentosos, como aspergilose, fusariose e zigomicose, ocorrem em pacientes com neutropenia prolongada e em 
pacientes com grave depressão na imunidade mediada por linfócitos $\mathrm{T}$, como ocorre em pacientes com doença enxerto contra hospedeiro. ${ }^{74}$

É recomendável o uso de fluconazol para a profilaxia de candidíase invasiva na fase de neutropenia do TCTH alogênico AI. ${ }^{75,76}$ A dose varia de 200 (BI) a $400 \mathrm{mg}$ (AI) ao dia. Doses $<200$ mg não são recomendadas (DII). O início da profilaxia deverá ser concomitante ao condicionamento, podendo ser estendida até o $\mathrm{D}+75$ pós-TCTH. ${ }^{77}$

A utilização de profilaxia em TCTH autólogo é opcional (CIII), podendo ser priorizada apenas em situações de maior risco, como mucosite gastrointestinal intensa, manipulação in vitro do enxerto, ou uso de análogo da purina (fludarabina ou 2-CDA) nos últimos seis meses pré-TCTH (BIII).

Uma alternativa ao fluconazol é a micafungina (BI), equinocandina já testada no contexto do TCTH e que mostrou resultados comparáveis ao fluconazol profilático. Entretanto, esta droga só está disponível na formulação venosa. $^{78}$

Itraconazol oral não é recomendado como droga profilática nesta fase por apresentar baixa tolerância, com muita toxicidade ${ }^{79}$ e no Brasil só haver a disponibilidade da formulação cápsula com baixa biodisponibilidade.

No contexto de risco para fungos filamentosos, como os TCTH alogênicos, a utilização de drogas com espectro também para fungos filamentosos consiste em uma melhor opção ao fluconazol. No entanto, existem poucos ensaios clínicos publicados em TCTH. Dados preliminares de um estudo clínico em 600 pacientes submetidos a TCTH alogênico, voriconazol oral foi comparado ao fluconazol como profilaxia, e este braço terapêutico obteve menos casos de aspergilose (BI). ${ }^{80}$ Outro azólico de nova geração, o posaconazol, foi estudado em pacientes com leucemia mieloide aguda ou mielodisplasia em indução de remissão, e demonstrou melhora em sobrevida quando comparado a fluconazol profilático. Ainda não existem dados em TCTH, porém esperam-se resultados semelhantes (BI). ${ }^{81}$

1. Profilaxia para TCTH alogênico: fluconazol $400 \mathrm{mg} /$ dia (AI) do condicionamento ao D+75; fluconazol entre 200 e $400 \mathrm{mg}$ (BI); voriconazol $200 \mathrm{mg} 2 \mathrm{x} /$ dia ou posaconazol $200 \mathrm{mg}$ $3 \mathrm{x} /$ dia (BI) para alto risco de infecção por fungo filamentoso (neutropenia $>14$ dias, uso crônico de corticoesteroides);

2. Profilaxia para TCTH autólogo: opcional na dose 200-400mg/dia (CIII). Para pacientes com uso prévio de análogos da purina (<6 meses) ou manipulação in vitro do enxerto, é recomendado (BIII).

\section{Uso de terapias empíricas ou específicas: Manejo durante o período de neutropenia}

Nesta fase, o paciente deverá ser manejado da mesma forma como é abordado um paciente neutropênico não submetido a TCTH, sendo as medidas terapêuticas necessárias precocemente com o intuito de reduzir mortalidade.
Atualmente, diversas estratégias terapêuticas estão sendo discutidas para o tratamento do neutropênico, e as recomendações atuais sobre manejo das principais síndromes infecciosas são:

- Neutropenia febril: antibiótico empírico inicial e modificações

- No desenvolvimento de febre durante a neutropenia a recomendação é iniciar imediatamente antibiótico empírico de amplo espectro (AI). O procedimento diagnóstico mandatário que deverá ocorrer previamente ao início da terapia é a coleta de hemocultura.

- A escolha da droga inicial deve ser baseada em avaliações de risco ${ }^{82,83}$ e sofre influência de fatores epidemiológicos locais e de fatores relacionados ao paciente individualmente. ${ }^{84}$

- As opções terapêuticas incluem os betalactâmicos: cefepime, ceftazidima, piperacilina-tazobactam e os carbapenêmicos, em monoterapia (AI). Estudos recentes discutem a melhor opção terapêutica. ${ }^{85,86}$

1. Com base nestes estudos, a recomendação mais forte é a utilização de piperacilina-tazobactam (BI) ou cefepime (BI) como droga empírica em monoterapia.

2. Utilização de carbapenêmicos como droga empírica inicial não é encorajada, principalmente devido à sua associação com colite pseudomembranosa (CI). Esta classe de drogas deverá ser restrita a falha terapêutica ou a situações epidemiológicas específicas, como surtos de enterobactérias com betalactamase de espectro expandido (ESBL) ${ }^{86}$

3. Não há nenhuma recomendação de modificação do esquema empírico em casos de utilização de profilaxia antimicrobiana prévia com quinolona, pois não existem dados sobre mudança no perfil de suscetibilidade a betalactâmicos após a utilização de quinolonas profiláticas para neutropenia febril hoje disponíveis. ${ }^{67}$

4. Terapia combinada não está indicada, tanto para a combinação ß-lactâmico + aminoglicosídeo (D1) ou ß-lactâmico + vancomicina $(\mathrm{C} 1) \cdot{ }^{87-90} \mathrm{~A}$ vancomicina não deve fazer parte da escolha empírica inicial pelo risco de selecionar cepas de enterococos resistentes e por não demonstrar nenhum benefício em relação à mortalidade e ao tempo para resolução da febre, já demonstrado em ensaio clínico randomizado C1. ${ }^{90,91}$

5. Está recomendada associação de glicopeptídio (vancomicina ou teicoplanina) apenas para as seguintes situações: a) em pacientes com sepse grave; ou b) quando há isolamento de cocos Gram-positivos resistentes, particularmente estafilococos meticilino-resistentes; ou c) se há suspeita de infecção por estes germes, como no caso de infecções relacionadas a catéter venoso central.

No entanto, toda decisão sobre a escolha da droga empírica a ser utilizada deverá ser guiada pela epidemiologia local de cada centro.

As recomendações sobre modificações no esquema inicial também foram revistas recentemente: 
1. Alteração do esquema empírico é justificável se houver evidência de piora clínica, identificação microbiológica de agente resistente ou evidência de toxicidade por droga (BII).

2. Em situações de mucosite gastrointestinal grave, quando há suspeita de tiflite, a introdução da droga metronidazol associada é fortemente recomendada.

3. Utilização de glicopeptídeo apenas por persistência de febre após 48 a 72 horas não está recomendada (DI). ${ }^{90}$

$\mathrm{O}$ ajuste do antimicrobiano em situações de documentação de infecção deverá ser feito de acordo com o antibiograma; porém, o uso de antimicrobiano de amplo espectro (cefepime, ceftazidima, piperacilina-tazobactam ou carbapenêmicos) deverá ser mantido até a recuperação neutrofílica. Diversos estudos já demonstraram que pacientes com bacteremia ou com infecção documentada demoram cerca de cinco dias para resolver a febre; portanto, não é indicada troca de antimicrobiano apenas por persistência de febre se o espectro antimicrobiano está adequado e o estado geral está mantido. ${ }^{92,93}$ Diminuição do espectro antimicrobiano só deverá ocorrer após resolução da neutropenia.

Introdução de antifúngicos empíricos será discutida na seção seguinte.

A duração do tratamento antimicrobiano deverá ser guiada pela documentação de infecção (pelos Critérios do Imunucompromised Host Society) e pela recuperação neutrofilica (neutr $>500$ celulas $/ \mathrm{mm}^{3}$ ). ${ }^{94,95}$

1. Em pacientes sem documentação de infecção (FOO) e com recuperação neutrofílica, a antibioticoterapia deverá ser suspensa (BII).

2. Em casos de documentação de infecção, o tempo de tratamento dependerá do tipo de infecção, porém não é recomendada suspensão de antimicrobiano antes da recuperação da neutropenia (BII).

3. Paciente com perspectiva de neutropenia prolongada, afebril, sem nenhuma documentação de infecção e estável, a utilização de antimicrobiano poderá ser suspensa após cinco a sete dias (CIII). Neste caso anterior, também é recomendado por especialistas a troca do antimicrobiano empírico por antibiótico profilático (CIII).

4. Não é recomendada a suspensão da droga em pacientes com instabilidade hemodinâmica, mucosite ou outro fator de risco para infecção (CIII) ${ }^{93}$

Vale ressaltar que a documentação de infecção é prioritária para a avaliação do episódio de neutropenia febril; portanto, coleta de hemocultura inicial, na persistência de febre, e a realização de exames de imagem são essenciais para adequada condução terapêutica nesta situação.

\section{- Manejo das infecções fúngicas na neutropenia}

Infecções fúngicas no neutropênico são classicamente associadas a alta mortalidade, o que resultou na indicação de terapia antifúngica empírica em pacientes neutropênicos com persistência de febre. ${ }^{93}$ No entanto, recentemente esta medida tem sido revista, e a terapia preemptiva é cada vez mais utilizada. Na terapia empírica, a presença de febre não responsiva a antibióticos é o gatilho para o início da terapia antifúngica. Já na estratégia preemptiva, outros marcadores de infecção são utilizados, como a presença de biomarcadores positivos (beta 1,3 glucana, galactomanana ou PCR para fungo), dados radiológicos (tomografias de tórax e seios da face) e dados clínicos. ${ }^{96}$ Esta nova estratégia de tratamento já demonstrou diminuir a utilização de antifúngicos sem impactar em mortalidade relacionada a infecção fúngica..$^{97,98}$

Atualmente as recomendações para o início de terapia antifúngica em neutropênicos deverão ser guiadas pela suspeita clínica de candidíase invasiva ou de infecção fúngica por fungo filamentoso:

- Iniciar antifúngico se houver suspeita de candidíase invasiva, definida como presença de febre persistente ou recorrente a despeito de antibióticos em pacientes com neutropenia + mucosite se não estiverem recebendo fluconazol profilático (AI). Nesta situação, as opções terapêuticas são: uma equinocandina (AI) ou uma preparação lipídica de anfotericina B (AI). ${ }^{99-101} \mathrm{O}$ uso de anfotericina B em deoxicolato deve ser desconsiderado, especialmente se o paciente está recebendo drogas nefrotóxicas concomitantes, tem doença de base com alto risco de insuficiência renal ou tem disfunção renal prévia (DII).

- Pacientes que preencham os seguintes critérios: Febre persistente ou recorrente a despeito de antibióticos em pacientes com neutropenia prolongada SE não estiverem recebendo voriconazol ou posaconazol profilático e apresentarem neutropenia superior a dez dias, é recomendado iniciar terapia antifúngica empírica com espectro para fungo filamentoso (AI); em pacientes com menos de dez dias de neutropenia, não está recomendado, a menos que tenha algum sinal clínico sugestivo (BIII). Nesta indicação de terapia empírica, estão disponíveis as seguintes opções terapêuticas: equinocandina (AI), preparação lipídica de anfotericina B (AI) e anfotericina $B$ desoxicolato. ${ }^{100,101}$ Pacientes com drogas nefrotóxicas concomitantes, doença de base com alto risco de insuficiencia renal ou com disfunção renal prévia não devem receber anfotericina $\mathrm{B}$ em deoxicolato (DII).

- Em instituições que optarem pela terapia preemptiva, a sugestão é monitorização com galactomanana 2-3x/semana (BII) e monitorização com tomografia computadorizada de tórax para aqueles com febre persistente ou recorrente, independente de terem sintomas respiratórios (AII).

Em situações com documentação de infecção fúngica, as recomendações são as seguintes:

- Para aspergilose invasiva: voriconazol IV ou VO ( $6 \mathrm{mg} / \mathrm{kg} \mathrm{12/12} \mathrm{h} \mathrm{no} \mathrm{primeiro} \mathrm{dia} \mathrm{e} \mathrm{após} 4 \mathrm{mg} / \mathrm{kg}$ 12/12 h) (AI), ${ }^{102}$ porém, em pacientes graves, usar IV no início (AIII); L-AMB (3 mg/kg/d) (BI). Avaliar necessidade de terapia combinada se o paciente não responde à terapia (BII). 
- Para candidíase invasiva: tratar com equinocandina (caspofungina, micafungina ou anidulafungina) se: profilaxia com fluconazol prévia (maior risco de C. glabrata ou $C$. krusei) ou paciente instável (AI); ${ }^{99,103}$ outras opções são: AMB (BI) ou voriconazol (para pacientes sem fluconazol prévio) (BI). Fluconazol terapêutico poderá ser dado a pacientes estáveis e sem exposição prévia a azólico (AI)

- Fusariose: Não há consenso sobre a droga de escolha. Entretanto, como dados in vitro sugerem que Fusarium solani, a espécie mais frequente, tem suscetibilidade reduzida aos azólicos, é mais prudente iniciar o tratamento com uma preparação lipídica de anfotericina B (3-5 mg/kg) AIII. Outra opcão é voriconazol IV ou VO $(6 \mathrm{mg} / \mathrm{kg} 12 / 12 \mathrm{~h} \mathrm{D} 1 \rightarrow 4 \mathrm{mg} / \mathrm{kg}$ $12 / 12$ h) (BIII). Considerar terapia combinada se paciente não responde à terapia (BIII). ${ }^{104,105}$

- Zigomicose: A única opção terapêutica no momento é uma preparação lipídica de anto B (3-5 mg/kg, dependendo da preparação (AII). Posaconazol VO é uma opção na terapia de resgate. ${ }^{106}$

\section{- Manejo das infecções virais na neutropenia}

Durante o período de neutropenia, algumas infecções virais requerem manejo especial. Entre elas citam-se as infecções latentes que se reativam, podendo causar doença nesse período (HSV e HHV-6), e as infecções pelos vírus da hepatite $\mathrm{B}$ e $\mathrm{C}$, estas últimas especialmente no contexto da prevenção de sua transmissão ao receptor.

\section{$H S V$}

1. O diagnóstico de doença pelo HSV deve ser feito pela detecção do vírus em biópsia de tecidos, por isolamento viral ou imuno-histoquímica com anticorpos monoclonais.

2. A localização da doença pelo HSV é importante na indicação do antiviral, dose e tempo de tratamento, conforme quadro abaixo.

3. Cepas de HSV resistentes ao aciclovir devem ser tratadas com o foscarnet endovenoso $(40 \mathrm{mg} / \mathrm{kg}$ a cada 8 horas ou $60 \mathrm{mg} / \mathrm{kg}$ a cada 12 horas por 7 a 21 dias, ou até cicatrização das lesões) (BIII).

4. No caso de resistência ao foscarnet, o tratamento deve ser feito com o cidofovir $(5 \mathrm{mg} / \mathrm{kg}$ uma vez por semana por duas semanas e, a seguir, uma vez por semana a cada duas semanas), sempre associado ao probenecid e com boa hidratação do paciente (BIII).

5. No caso de lesões cutâneas de HSV resistentes ao aciclovir, mas de fácil acesso, o tratamento pode ser feito topicamente com cidofovir gel $(0,3 \%$ ou $1 \%)$ uma vez ao dia, ou com solução oftálmica de trifluridina (5\%) a cada 8 horas.

\section{$H H V-6$}

O herpes humano 6 (HHV-6) é o agente causador do exantema subitum e geralmente todas as crianças se infectam até os três anos de idade. A reativação póstransplante ocorre entre $30 \%$ a $60 \%$ dos receptores e os quadros mais consistentemente associados ao HHV-6 são o retardo na enxertia de plaquetas e monócitos, rash cutâneo e encefalite. Outras manifestações frequentemente relatadas são pneumonia intersticial idiopática, febre e hepatite, porém com menor evidência de associação com o HHV-6. ${ }^{107}$ Estudos recentes sugerem que a reativação do HHV-6 é muito mais frequente em receptores de transplante de sangue de cordão umbilical, com taxas de reativação de mais de $90 \% .^{108}$

1. Viremia intermitente ocorre mesmo em hospedeiros imunocompetentes e a detecção de HHV-6 em amostras de sangue por PCR qualitativo tem pouco valor no diagnóstico de reativação (BII). ${ }^{109}$

2. O diagnóstico de reativação de infecção pelo HHV-6 deve ser feito por PCR quantitativo em amostras de sangue total, plasma ou soro (BII).

3. O diagnóstico de encefalite é feito pela detecção de HHV-6 por PCR qualitativo ou quantitativo em líquor em presença de alterações neurológicas variadas e de imagens na ressonância magnética (BII).

4. Suspeita-se que o HHV-6 pode ser o causador da falha de enxertia quando se detecta reativação por este agente no período de neutropenia (BIII).

5. No momento não se recomenda vigilância de HHV-6 em receptores de TCTH. Entretanto, é possível que receptores de transplante de sangue de cordão se beneficiem desta estratégia para introdução precoce de antiviral (CIII).

6. O tratamento de doença pelo HHV-6 pode ser feito com o ganciclovir ( $5 \mathrm{mg} / \mathrm{kg} \mathrm{2x/d)} \mathrm{ou} \mathrm{o} \mathrm{foscarnet}(60 \mathrm{mg} / \mathrm{kg}$ $3 \mathrm{x} / \mathrm{d}$ ) por pelo menos três semanas (BII).
Tratamento de HSV durante a neutropenia no paciente submetido a TCTH

\begin{tabular}{|c|c|c|}
\hline Local & Tratamento & Alternativa \\
\hline $\begin{array}{l}\text { Doença mucocutãnea } \\
\text { ou esofágica }\end{array}$ & $\begin{array}{c}\text { Aciclovir endovenoso }(250 \mathrm{mg} / \mathrm{m} \\
5 \mathrm{mg} / \mathrm{kg} \text { a cada } 8 \text { horas }) \text { por } 7 \text { a } 10 \text { dias } \\
\text { ou o aciclovir oral }(5 \times 200 \mathrm{mg} / \mathrm{d} \mathrm{a} \\
5 \times 400 \mathrm{mg} / \mathrm{d}) \text { por } 10 \mathrm{dias}(\mathrm{Al})\end{array}$ & $\begin{array}{l}\text { Valaciclovir ou famciclovir na } \\
\text { dose de } 5 \times 200 \mathrm{mg} / \mathrm{d} \\
\text { por } 10 \text { dias (BIII) }\end{array}$ \\
\hline $\begin{array}{l}\text { Pneumonia, hepatite, } \\
\text { meningite ou encefalite }\end{array}$ & $\begin{array}{l}\text { Aciclovir endovenoso ( } 500 \mathrm{mg} / \mathrm{m} \\
\text { ou } 10 \mathrm{mg} / \mathrm{kg} \text { a cada } 8 \text { horas) } \\
\text { por } 14 \text { a } 21 \text { dias (All) }\end{array}$ & \\
\hline
\end{tabular}

Hepatites $B$ e $C$

Logo após a infusão do enxerto e durante o período de neutropenia, devem receber atenção especial os receptores de TCTH soronegativos para os vírus das hepatites $\mathrm{B}$ e/ou $\mathrm{C}$, cujos doadores foram identificados como $\mathrm{HBsAg}$ positivos e/ou anti-HCV positivos. 
$H B V$

1. Mesmo que o doador HBsAg positivo tenha sido tratado com lamivudina ou entecavir antes da doação das células-tronco hematopoéticas, o receptor deve receber imunoglobulina específica (HBIg) na dose de $0,06 \mathrm{ml} / \mathrm{kg}$ imediatamente antes da infusão do enxerto (AIII).

2. Se no momento da coleta o doador for HBsAg ou HBV-DNA negativo, o receptor deve ser monitorizado mensalmente com ALT e, em caso de ascensão de enzimas, deve ser feita a pesquisa de HBV-DNA ou HBsAg (AIII).

3. Havendo positivação dos marcadores, o receptor deve ser tratado com lamivudina ( $100 \mathrm{mg} / \mathrm{dia})$ por seis meses (TCTH autólogo), por seis meses após a retirada da imunossupressão (TCTH alogênico) e por tempo mais prolongado em receptores de TCTH alogênico recebendo imunossupressão por DECH crônica (BIII).

4. Se no sexto mês pós-TCTH o receptor não apresentar marcadores de infecção pelo HBV deve receber o esquema convencional de vacinação (três doses) (BII).

5. Se o doador ou a bolsa de células tronco-hematopoéticas testarem positivas no momento do transplante, o receptor deve receber profilaxia com lamivudina do dia zero até seis meses após o término da imunossupressão. Uma segunda dose de HBIg pode ser feita quatro semanas após a infusão do enxerto (AIII).

\section{$\mathrm{HCV}$}

1. Não há evidência de maior morbidade da hepatite $\mathrm{C}$ no período de neutropenia, o que não descarta a necessidade de acompanhamento do receptor. Mesmo que o doador anti$\mathrm{HCV}$ positivo tenha recebido tratamento antes da coleta das células-tronco hematopoéticas, o receptor deve ser monitorizado por PCR para $\mathrm{HCV}$ mensalmente até o $6^{\circ}$ mês pósTCTH(BIII).

\section{Manejo na fase II (pós-pega)}

$\mathrm{Na}$ fase pós-enxertia, o risco de infecção é principalmente devido à lenta recuperação da imunidade humoral e celular. Nesta fase está a principal diferença entre os transplantes autólogo e alogênico. Pacientes submetidos a TCTH autólogo apresentam reconstituição imune mais rápida, enquanto receptores de TCTH alogênico têm recuperação mais lenta, especialmente se apresentam DECH. Portanto, as recomendações serão guiadas pelo tipo de transplante, pela presença de $\mathrm{DECH}$, e se o paciente está recebendo alguma droga imunossupressora. Nesta fase os pacientes devem receber vacinas.

\section{- Manejo da infecção bacteriana: profilaxias}

Em pacientes submetidos a TCTH autólogo não há recomendação de nenhuma medida específica quanto a profilaxia, exceto vacinação (vide tópico vacinas). Em pacientes submetidos a TCTH alogênico, a dosagem do nível sérico de Ig G poderá ser utilizada para avaliar o risco de infecção e a necessidade de reposição. Para pacientes com hipogamaglobulinemia (IgG sérico $<400 \mathrm{mg} / \mathrm{dl}$ ) é recomendado IVIG $500 \mathrm{mg} / \mathrm{kg} / \mathrm{mês}$. Esta é uma intervenção de alto custo, porém associada a diminuir do número de episódios infecciosos. Não é recomendada a utilização de IVIG em transplante autólogo ou em alogênico sem documentação de hipogamaglobulinemia (DI). ${ }^{110,111}$ Uso de antimicrobianos profiláticos está recomendado apenas em pacientes com DECH, para prevenção de $S$. pneumoniae. Nesta situação, o recomendado é a utilização de penicilina oral 250-500 mg duas vezes ao dia (AIII), e como alternativa macrolídios, quinolonas ou cefalosporinas de segunda geração (CIII). ${ }^{112-115}$ A profilaxia deverá ser utilizada até a interrupção das drogas imunossupressoras para o tratamento da doença enxerto (AIII).

\section{- Manejo das infecções fúngicas: profilaxias e tratamento preemptivo}

Poucos pacientes submetidos a TCTH têm indicação de profilaxia estendida para candidíase na fase II e III pós transplante. $\mathrm{O}$ risco principal está associado à presença de $\mathrm{DECH}$ do trato gastrointestinal grave.

Nestas situações, a opção é profilaxia com fluconazol $400 \mathrm{mg} / \mathrm{d}(\mathrm{AI})$

Pacientes com alto risco de desenvolvimento de $\mathrm{DECH}$ grave (doadores não aparentados, transplante não compatível, haploidêtico) são considerados de alto risco para desenvolvimento de infecção fúngica invasiva na fase póspega, e, portanto, profilaxia com drogas com ação contra fungos filamentosos deve ser avaliada (BI). ${ }^{116}$ Recomendase posaconazol (200 mg VO 3x/d) (BI) ou voriconazol (BI), assim como monitorização com galactomanana (BI)

A recomendação terapêutica para infecções documentadas é a mesma da descrita no tópico manejo das infecções fúngicas na neutropenia.

- Manejo da infecção viral: profilaxias, tratamento preemptivo e tratamento específico de viroses documentadas

Após a enxertia, os vírus que requerem atenção especial são CMV, EBV, VZV, poliomavírus, os vírus das hepatites B e $\mathrm{C}$ e os vírus respiratórios.

CMV

Receptores de TCTH soropositivos para o CMV e receptores soronegativos com doador soropositivo estão sob risco de adoecimento e óbito pelo CMV e estratégias de controle devem ser adotadas. Tanto o uso de profilaxia como o tratamento preemptivo com ganciclovir estão indicados. A profilaxia visa inibir a reativação do $\mathrm{CMV}$ enquanto a estratégia preemptiva visa inibir o adoecimento 
pelo CMV pelo tratamento precoce no caso de detecção de viremia pela vigilância viral.

\section{Tratamento preemptivo}

1. A vigilância do CMV requer técnicas sensíveis e específicas capazes de diagnosticar rapidamente o início da replicação viral permitindo a introdução precoce de ganciclovir endovenoso.

2. As técnicas recomendadas para a vigilância do CMV são a detecção de pp65 (antigenemia), detecção de CMVDNA por PCR ou PCR em tempo real ou detecção de CMVRNA. ${ }^{21,117,118}$ Centros de TCTH realizando transplantes alogênicos devem ter estrutura para realizar ao menos um destes testes (AIII).

3. A vigilância viral deve ser feita desde o condicionamento até o $\mathrm{d}+100$, seguida de introdução de antiviral (ganciclovir endovenoso) frente a detecção de viremia por qualquer técnica acima mencionada (AI).

4. O tratamento preemptivo deve ser administrado na dose de $5 \mathrm{mg} / \mathrm{kg} /$ dose duas vezes por dia no mínimo por duas semanas ${ }^{21}$ (AI). Se o CMV ainda for detectável após duas semanas, pode ser mantido o tratamento até a negativação do teste ${ }^{119}$ ou até o d+100.

5. Receptores de TCTH autólogo, recentemente expostos a irradiação corporal total (TBI), fludarabina ou 2clorodeoxiadenosina, também devem fazer vigilância de CMV com antigenemia. Neste grupo, tratamento preemptivo com GCV deve ser introduzido se antigenemia $\geq 5$ células positivas. No caso de seleção de células CD34+, introduzir GCV com qualquer nível de antigenemia. ${ }^{120}$
6. Caso se opte pelo esquema preemptivo intermitente (tratamento de cada episódio de detecção de CMV), a vigilância viral deve ser mantida até o dia +100 porque as recidivas de viremia são frequentes ${ }^{121}(\mathrm{BII})$

7. Pacientes intolerantes ao GCV devem receber foscarnet (AI).

8. Pacientes recebendo GCV devem ter contagem de leucócitos pelo menos duas vezes por semana (BIII). No caso de aparecimento de neutropenia $\left(<1.000 / \mathrm{mm}^{3}\right)$, o tratamento pode ser suspenso por dois dias até que o número de neutrófilos atinja $1.000 / \mathrm{mm}^{3}$ por dois dias consecutivos, quando então o GCV pode ser reintroduzido. O uso de G-CSF pode ajudar no manejo da neutropenia induzida pelo GCV.

9. Fatores de risco para adoecimento após o d +100 incluem DECH crônica, CD4 $<50 / \mathrm{mm}^{3}$, enxerto de doador soronegativo em receptor soropositivo, transplantes não aparentados, haploidênticos, de sangue de cordão ou depletados de células T. ${ }^{121-123}$

\section{Profilaxia}

1. Caso se opte pela profilaxia da reativação do CMV, esta deve ser feita preferencialmente com o ganciclovir endovenoso $(5 \mathrm{mg} / \mathrm{kg} / \mathrm{dose})$ duas vezes por dia por 5 a 7 dias (indução) e depois uma vez por dia até o d+100 (AI).

2. O uso de profilaxia não exclui a necessidade de vigilância viral especialmente se outros antivirais que não o ganciclovir endovenoso forem utilizados.

3. Drogas alternativas na profilaxia e tratamento preemptivo para controle do CMV estão indicados no quadro abaixo.

Estratégias de controle de CMV na fase pós- pega do TCTH

\begin{tabular}{|c|c|c|}
\hline $\begin{array}{c}\text { Estratégia de controle } \\
\text { de CMV }\end{array}$ & Antiviral recomendado & Alternativas \\
\hline Profilaxia & $\begin{array}{l}\text { Ganciclovir (GCV) endovenoso ( } 5 \mathrm{mg} / \mathrm{kg} / \mathrm{dose} \text { ) } 2 \text { vezes por } \\
\text { dia, por } 5 \text { a } 7 \text { dias (indução), seguido de } 5 \mathrm{mg} / \mathrm{kg} / \mathrm{dia} \text { até o } \\
\text { d+100 (Al) }\end{array}$ & $\begin{array}{l}\text { Aciclovir endovenoso ( } 500 \mathrm{mg} / \mathrm{m}^{2} \text { a cada } 8 \text { horas) por } \\
7 \text { a } 10 \text { dias ou o aciclovir oral, } 800 \mathrm{mg} 4 \times / \mathrm{d}(>40 \mathrm{~kg}) \text { ou } \\
600 \mathrm{mg} 4 \mathrm{x} / \mathrm{d}(<40 \mathrm{~kg})(\mathrm{Cl}) \\
\text { Valaciclovir oral de } 2 \mathrm{~g} 3 \text { a } 4 \text { vezes por dia }(>40 \mathrm{~kg}) \text { até } \\
\text { o d }+100(\mathrm{Cl}) \\
\text { Foscarnet } 60 \mathrm{mg} / \mathrm{kg} \text { endovenoso } 2 \text { vezes por dia por } \\
7 \text { dias, seguido de } 90-120 \mathrm{mg} / \mathrm{kg} \text { uma vez por dia até } \\
\mathrm{d}+100 \text { (CIII) }\end{array}$ \\
\hline Preemptivo & $\begin{array}{l}\text { Indução: Ganciclovir (GCV) endovenoso } 5 \mathrm{mg} / \mathrm{kg} / \text { dose duas } \\
\text { vezes por dia por } 14 \text { dias ou } 5 \mathrm{mg} / \mathrm{kg} / \text { dose } 2 \text { vezes por dia, } \\
\text { por } 7 \text { dias (Al) } \\
\text { Manutenção: GCV } 2 x / \mathrm{d} \text { por } 2 \text { semanas se indução de } 14 \\
\text { dias ou por } 3 \text { semanas se indução de } 7 \text { dias (Al) } \\
\text { Obs: Os testes de detecção CMV devem estar negativos } \\
\text { antes da interrupção da terapia }\end{array}$ & $\begin{array}{l}\text { Foscarnet, EV (Al) } \\
\text { Indução: } 60 \mathrm{mg} / \mathrm{kg} 2 \times / \text { dia } \\
\text { Manutenção: } 90 \mathrm{mg} / \mathrm{kg} / \mathrm{dia} \\
\text { Valganciclovir (oral) (>40 kg) (BII) } \\
\text { Indução: } 900 \mathrm{mg} 2 \times / \text { dia } \\
\text { Manutenção: } 900 \mathrm{mg} / \mathrm{dia} \\
\text { Cidofovir, EV (CII) } \\
\text { Indução: } 5 \mathrm{mg} / \mathrm{kg} \text { por semana, } 2 \text { doses } \\
\text { Manutenção: } 5 \mathrm{mg} / \mathrm{kg} \text { semanas alternadas. } \\
\text { (hidratação e probenecid como indicado) }\end{array}$ \\
\hline
\end{tabular}


$E B V$

1. A monitorização da carga viral do EBV deve ser feita por PCR quantitativo (em tempo real) em pacientes com dois ou mais fatores de risco para reativação de EBV e de doença linfoproliferativa pós-transplante, a saber: população pediátrica, receptor soronegativo com doador soropositivo, transplantes não aparentados ou com disparidade de HLA, transplantes haploidênticos e uso de ATG ou depleção de células T (BII).

2. Em caso de aumento da carga viral, recomenda-se (se possível) a redução da imunossupressão. Caso não haja resposta, a introdução de rituximab (uma dose de $375 \mathrm{mg} / \mathrm{m}^{2}$ ) pode prevenir a progressão para DLPT. ${ }^{124}$

3. Infusão de linfócitos do doador pode ser usada em associação com rituximab ou ser uma alternativa ao mesmo (CII).

4. Não está recomendado o uso de profilaxia ou tratamento com aciclovir uma vez que não existe resposta a esta intervenção (DII).

\section{$V Z V$}

Cerca de $50 \%$ dos receptores de TCTH soropositivos para o VZV desenvolvem herpes zoster (HZ) geralmente a partir do terceiro mês pós-transplante. O risco de disseminação ou visceralização da infecção aumenta dependendo do estado imunológico do paciente. $\mathrm{Na}$ suspeita deve-se introduzir medicação endovenosa. Em geral, a resposta ao tratamento com o aciclovir é boa e o risco de um segundo episódio de HZ é baixo.

1. A profilaxia prolongada com aciclovir por um ano é efetiva na supressão da reativação do VZV pós-transplante e pode ser utilizada em todos os tipos de TCTH (autólogo, alogênico, intensidade reduzida, etc) ${ }^{30}(\mathrm{AI})$.

2. A vacinação contra o VZV está preconizada para os familiares e acompanhantes suscetíveis a partir do momento em que a decisão do transplante for tomada e deve ser feita há mais de quatro semanas antes do início do condicionamento (BIII).
3. Como se trata de vacina de vírus vivos atenuados, seu uso em receptores de TCTH não é recomendado antes do segundo ano do transplante, quando em geral o paciente já apresentou quadro de HZ. Como é raro um segundo episódio de zoster, o benefício da vacina é marginal (EIII).

4. Pacientes com quadro de varicela ou de HZ devem ser colocados sob precauções respiratórias e de contato até que todas as lesões estejam sob a forma de crostas (AII).

5. Os antivirais e doses preconizadas para a profilaxia e tratamento do VZV estão descritas no quadro abaixo.

\section{Poliomavírus JC e BK}

Os poliomavírus JC (JCV) e BK (BKV) são ubíquos e a infecção em geral se dá nos primeiros anos de vida. Estimase que $50 \%$ a $90 \%$ da população mundial tenha sido exposta antes dos 10 anos de idade. ${ }^{125}$

Assim, a reativação da infecção é a principal causa do adoecimento pós-TCTH. A manifestação mais frequente é a cistite hemorrágica pelo BKV que ocorre geralmente entre a $3^{\mathrm{a}}$ e $6^{\mathrm{a}}$ semanas pós-transplante. Outras manifestações clínicas que ocorrem mais raramente são: nefropatia por BKV ou JCV e a leucoencefalopatia multifocal progressiva, geralmente mediada pela reativação do JCV, mas que também tem sido descrita para o BKV. ${ }^{126}$

1. Estudos avaliando um cut-off de carga viral de BKV para desenvolvimento de cistite hemorrágica encontraram os seguintes valores: acima de 107 cópias/mL em urina ou acima de 104 cópias em plasma. ${ }^{127,128}$ Entretanto, não há dados suficientes na literatura que justifiquem a vigilância de JCV ou BKV pós-TCTH para introdução de terapia antiviral preemptiva para evitar a cistite hemorrágica.

2. Fluoroquinolonas podem inibir a replicação de BKV in vitro (cultura) e há relatos de redução da carga viral de BKV em receptores de TCTH fazendo uso de profilaxia com ciprofloxacina. ${ }^{129}$ Entretanto, tal redução não se reflete na diminuição de cistite hemorrágica. Estudos prospectivos controlados são necessários para definir o benefício da profilaxia.

Tratamento e profilaxia da infecção por VZV em pacientes submetidos a TCTH

\begin{tabular}{|c|c|c|}
\hline Indicação & Drogas & Alternativas \\
\hline \multirow[t]{3}{*}{ Profilaxia } & Aciclovir (ACV) & Valaciclovir \\
\hline & $\begin{array}{l}\text { Adultos e adolescentes }(>40 \mathrm{~kg} \text { ): } 800 \mathrm{mg} \text { VO } \\
2 \mathrm{x} / \text { dia por um ano }\end{array}$ & Adultos e adolescentes (> $40 \mathrm{~kg}$ ): $500 \mathrm{mg}$ VO $2 x /$ dia por um ano \\
\hline & $\begin{array}{l}\text { Crianças }(<40 \mathrm{~kg}): 60-80 \mathrm{mg} / \mathrm{kg} \text { VO divididas em } \\
2-3 \text { doses diárias }\end{array}$ & Crianças (< $40 \mathrm{~kg})$ : $250 \mathrm{mg}$ VO 2x/dia \\
\hline $\begin{array}{l}\text { Profilaxia pós- } \\
\text { exposição }\end{array}$ & $\begin{array}{l}\text { Imunoglobulina hiper-imune específica (VZlg) } \\
\text { na dose de } 0,2 \text { a } 1 \mathrm{~mL} / \mathrm{kg} \text { até } 96 \mathrm{~h} \text { pós-exposição }\end{array}$ & $\begin{array}{l}\text { Profilaxia pós-exposição com ACV ou valaciclovir caso não tenha } \\
\text { sido feita VZlg. Pode ser feita até } 22 \text { dias pós-exposição (BIII) }\end{array}$ \\
\hline \multirow[t]{2}{*}{ Tratamento } & \multirow{2}{*}{$\begin{array}{l}\text { Aciclovir } \\
500 \mathrm{mg} / \mathrm{m}^{2} 8 / 8 \mathrm{~h} \text { até } 2 \text { dias após todas as } \\
\text { lesões estarem crostificadas }\end{array}$} & $\begin{array}{l}\text { Valaciclovir oral* } 1000 \mathrm{mg} 8 / 8 \mathrm{~h} \text { por } 7 \text { dias ou até } 2 \text { dias após } \\
\text { todas as lesões estarem crostificadas (CII) }\end{array}$ \\
\hline & & Aciclovir oral* $800 \mathrm{mg} 5 \mathrm{x} /$ dia por 7 a 10 dias (CII) \\
\hline
\end{tabular}

$\left({ }^{*}\right)$ em quadros controlados e estáveis de VZV 
3. Não há estudos controlados para definir o melhor tratamento para a cistite hemorrágica por BKV. Cidofovir tem sido usado nas doses de $1 \mathrm{mg} / \mathrm{kg}$ três vezes por semana (sem probenecid) ou $5 \mathrm{mk} / \mathrm{kg}$ por semana (com probenecid).

\section{Hepatites $B$ e $C$}

$\mathrm{Na}$ fase precoce do transplante, receptores soropositivos para os vírus das hepatites $\mathrm{B}$ e/ou C podem apresentar intensa replicação viral nos hepatócitos. Portanto, a retirada da imunossupressão deve ser cuidadosa para evitar agressão imune aos hepatócitos.

\section{$H B V$}

1. O risco de reativação do HBV em receptores antiHBs e anti-HBc positivos é considerado alto se houver tratamento prolongado com corticosteroides, como na DECH crônica ou após o uso de fludarabina, rituximab ou alemtuzumab. Nestes casos, os pacientes devem ser monitorizados com ALT e, em caso de alteração, realizar a pesquisa de HBV-DNA e tratamento com lamivudina se a PCR for positiva.

2. A duração do tratamento recomendada é de pelo menos seis meses após o TCTH em receptores de transplante autólogo, seis meses após a interrupção das drogas imunossupressoras em receptores de transplante alogênico e por tempo prolongado nos que mantêm imunossupressores por causa de DECH crônica. ${ }^{130}$ (BIII).

3. Os níveis de anti-HBs devem ser monitorizados a cada três meses e, se houver evidência de queda, recomenda-se fazer a PCR para deteç̧ão de HBV-DNA. Pacientes com perda do anti-HBs e PCR para HBV-DNA negativa devem receber vacinação na tentativa de restaurar a imunidade (BIII).

\section{$\mathrm{HCV}$}

1. $\mathrm{O}$ tratamento da hepatite $\mathrm{C}$ no período pós-TCTH deve ser considerado se o paciente estiver em remissão completa, com pelo menos dois anos após o transplante, sem evidência de $\mathrm{DECH}$, sem uso de imunossupressores há pelo menos seis meses, e com hemograma e creatinina sérica normais (BIII).

2. O tratamento deve ser feito com doses plenas de ribavirina e interferon peguilado, modificadas de acordo com surgimento de eventos adversos e por 24 a 48 semanas, dependendo da resposta (BIII).

\section{Viroses respiratórias}

Acometem o receptor de TCTH a qualquer momento durante o seguimento. Mais de 15 vírus respiratórios (VR) são conhecidos. O quadro a seguir mostra a distribuição dos VR de acordo com a família e, em negrito, os VR descobertos mais recentemente. Ultimamente discute-se o papel dos minivírus, descritos em 2004, como possíveis agentes nas pneumonias em pacientes com ventilação assistida. ${ }^{131,132}$

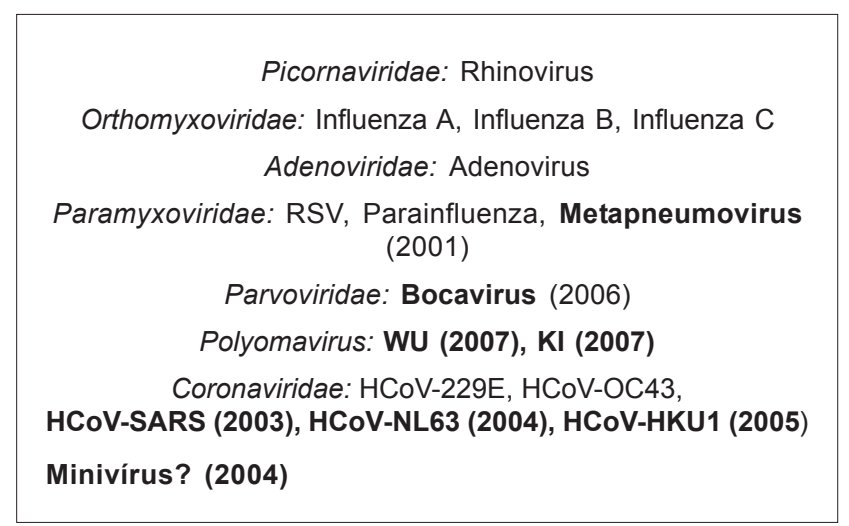

Apresentam comportamento sazonal, que varia de acordo com o vírus em questão e com a latitude. Alguns apresentam sazonalidade bem marcada em determinadas regiões, tais como o vírus respiratório sincicial (RSV) em regiões de clima temperado ou subtropical. ${ }^{133,134}$ Outros circulam com maior intensidade no inverno, embora possam ser detectados em qualquer época do ano, tais como influenza, rinovírus, parainfluenza, etc. Nas regiões tropicais, os vírus respiratórios circulam com maior intensidade no período das chuvas. ${ }^{135}$

No Brasil, nem todos os centros de TCTH têm estrutura para diagnóstico das viroses respiratórias. Assim, é importante ressaltar que as taxas de incidência dos VR nessa população estão certamente subestimadas em nosso país, assim como as complicações decorrentes destas infecções. $\mathrm{O}$ uso de imunossupressores favorece a infecção persistente e excreção prolongada dos VR facilitando a transmissão. O diagnóstico permite a intervenção precoce com antivirais e a implantação de medidas de controle da transmissão no ambiente hospitalar.

1. As infecções pelo RSV, parainfluenza, influenza A e $\mathrm{B}$, adenovírus e metapneumovírus são relevantes no receptor de TCTH.

2. As técnicas diagnósticas mais recomendadas são a imunofluorescência direta ou indireta com anticorpos monoclonais e a PCR ou PCR em tempo real.

3. Os vírus respiratórios passíveis de tratamento com antivirais são RSV parainfluenza e influenza. Para os outros vírus respiratórios as informações são escassas.

4. A ribavirina inalatória é a droga usada no tratamento das infecções pelo RSV e parainfluenza. No caso de RSV recomenda-se o tratamento com o objetivo de impedir a progressão para pneumonia (CIII). Estão especialmente sob maior risco de pneumonia e óbito pelo RSV aqueles infectados pelo RSV antes da enxertia, com linfopenia ou em uso de altas doses de drogas imunossupressoras. ${ }^{71}$ Optando-se pelo tratamento, este deve ser feito com a ribavirina inalatória $(60 \mathrm{mg} / \mathrm{mL}, 2 \mathrm{~g}$ total, $3 \mathrm{x} / \mathrm{d}$ por duas horas ou em nebulização contínua, overnight).

5. A profilaxia das infecções pelo RSV com o palivizumab tem sido usada em população pediátrica de TCTH, 
principalmente pelo alto custo desta medicação (doses por $\mathrm{kg}$ de peso) (CIII).

6. O tratamento das infecções pelos vírus da influenza pode ser feito com a amantadina (100 $\mathrm{mg} 2 \mathrm{x} / \mathrm{d})$, ou oseltamivir (75 mg $2 \mathrm{x} / \mathrm{d}$ ), por 5 a 10 dias. O vírus da influenza $\mathrm{B}$ não é sensível à amantadina e o tratamento deve ser feito com o oseltamivir que cobre influenza A e B. ${ }^{136,137}$

7. Em caso de surto hospitalar de influenza, recomendase profilaxia com oseltamivir $(75 \mathrm{mg}$ por dia) para receptores de TCTH antes do segundo ano do transplante ou com DECH crônica recebendo doses altas de imunossupressores (BII).

8. Embora com ação in vitro contra o adenovírus, drogas como a ribavirina, cidofovir, ganciclovir e vidarabina não estão oficialmente liberadas para uso no tratamento das infecções pelo adenovírus. ${ }^{138}$

9. As principais armas no controle das viroses respiratórias em receptores de TCTH são: vacinação anual contra influenza dos profissionais de saúde e contactuantes domiciliares do paciente, educação continuada e medidas estritas de controle da transmissão (isolamento de contato, cohorting de pacientes, lavagem de mãos, etc). ${ }^{139}$

- Vacinação no paciente transplantado

Abaixo seguem as recomendações quanto a vacinação em pacientes submetidos a TCTH autólogo e alogênico e para familiares, além das vacinas contraindicadas nestes contextos.

Vacinas recomendadas para receptores de TCTH autólogo e alogênico

\begin{tabular}{|c|c|c|c|c|}
\hline Vacina & $\begin{array}{l}\text { Recomendada para } \\
\text { uso pós-TCTH }\end{array}$ & $\begin{array}{l}\text { Tempo pós-TCTH } \\
\text { para iniciar } \\
\text { vacinação }\end{array}$ & $\begin{array}{l}\text { Número } \\
\text { de doses }^{1}\end{array}$ & $\begin{array}{l}\text { Resposta melhor se } \\
\text { doador for vacinado } \\
\text { antes da doação }\left(^{*}\right)\end{array}$ \\
\hline $\begin{array}{l}\text { Pneumocócica conjugada } \\
\text { heptavalente (PCV7) }\end{array}$ & $\operatorname{Sim}(\mathrm{BI})$ & $3-6$ meses & $3-4^{2}$ & $\begin{array}{l}\text { Sim, considerar se o } \\
\text { receptor tiver risco alto } \\
\text { para } \mathrm{DECH} \text { crônica }\end{array}$ \\
\hline $\begin{array}{l}\text { Tétano, difteria, } \\
\text { pertussis acelular }{ }^{3} \\
\text { (DTPa ou dT) }\end{array}$ & $\begin{array}{l}\text { Sim } \\
\text { Tétano-difteria: (BII) } \\
\text { pertussis (CIII) }\end{array}$ & $6-12$ meses & $3^{4}$ & $\begin{array}{l}\text { Tétano: provável } \\
\text { Difteria: provável } \\
\text { Pertussis: desconhecido }\end{array}$ \\
\hline $\begin{array}{l}\text { Haemophilus Influenzae } \\
\text { conjugada (HbCV) }\end{array}$ & $\operatorname{Sim}(B I I)$ & $6-12$ meses & 3 & Sim \\
\hline Meningocócica conjugada (MCV) & $\begin{array}{l}\text { Seguir recomendação local } \\
\text { para a população em geral (BII) }\end{array}$ & $6-12$ meses & 1 & Desconhecido \\
\hline Poliomielite inativada & $\operatorname{Sim}(B I I)$ & $6-12$ meses & 3 & Desconhecido \\
\hline Hepatite B recombinante & $\operatorname{Sim}(B I I)$ & $6-12$ meses & 3 & Provável 5 \\
\hline Hepatite A inativada & $\operatorname{Sim}(B I I)$ & 12 meses $(140)$ & $2^{6}$ & Desconhecido \\
\hline Influenza inativada & Anualmente (AlI) & 4-6 meses & $1-2^{7}$ & Desconhecido \\
\hline $\begin{array}{l}\text { Sarampo - caxumba - rubéola } \\
\text { (vírus vivos atenuados) }\end{array}$ & $\begin{array}{l}\text { Sarampo: Crianças e adultos } \\
\text { soronegativos } \\
\text { Sarampo: BII } \\
\text { Caxumba: CIII } \\
\text { Rubéola: BIII } \\
\text { EIII (<24 meses pós-TCTH, DECH } \\
\text { ativa, recebendo imunossupressão) }\end{array}$ & 24 meses & $1-2^{8}$ & Desconhecido \\
\hline
\end{tabular}

${ }^{1}$ Recomenda-se intervalo mínimo de um mês entre as doses

${ }^{2}$ Após 3 doses de PCV, pode ser utilizada uma dose de PPV23 (vacina pneumocócica de polissacáride 23-valente) para ampliar o espectro de proteção) (BII). Pacientes com DECH crônica que em geral respondem muito mal à PPV23, recomenda-se uma quarta dose de PCV em vez da PPV23 (CIII)

${ }^{3}$ DTPa é preferivel, entretanto no Brasil ainda não está prevista nos C.R.I.E.s para hospedeiros imunocomprometidos.

Para pacientes $>7$ anos usar a dupla tipo adulto (dT).

${ }^{4}$ Doses de reforço de dT a cada 10 anos são recomendadas, como para imunocompetentes (CIII)

${ }^{5}$ Melhor resposta do receptor à vacinação é observada se o doador receber mais de uma dose da vacina de hepatite $B$ antes da doação.

${ }^{6}$ Doses com intervalo de 6 a 12 meses. Doses pediátricas variam de acordo com o fabricante. Administrar imunoglobulina

$(0,02 \mathrm{ml} / \mathrm{kg}-0,06 \mathrm{ml} / \mathrm{kg})$ para receptores susceptíveis em situações de risco tais como viagem para áreas endêmicas ou pós-exposição.

${ }^{7}$ Crianças menores de 9 anos de idade, que nunca foram vacinadas contra a influenza, devem receber duas doses anuais da vacina com intervalo de um mês. Apenas uma dose é recomendada após a primovacinação ${ }^{141}$

${ }^{8} \mathrm{Em}$ crianças recomendam-se 2 doses. Em adultos, recomenda-se fazer sorologia de sarampo pelo menos a cada dois anos após a vacinação para avaliar necessidade de dose de reforço ${ }^{142,143}$ 
Vacinas opcionais ou não recomendadas para receptores de TCTH autólogo e alogênico

\begin{tabular}{|c|c|c|}
\hline Vacina & Recomendações & Nivel de evidência \\
\hline $\begin{array}{l}\text { Bacilo Calmette-Guérin (BCG) } \\
\text { (vivos atenuados) }\end{array}$ & Contraindicada para receptores de TCTH & Ell \\
\hline $\begin{array}{l}\text { Varicela } \\
\text { (Vírus vivos atenuados) }\end{array}$ & $\begin{array}{l}\text { Contraindicada antes do segundo ano pós-TCTH } \\
\text { Dados limitados sobre eficácia e segurança }\end{array}$ & $\begin{array}{l}\text { EIII (<24 meses pós-TCTH, ou DECH ativa } \\
\text { ou recebendo imunossupressão) } \\
\text { CIII ( }>24 \text { meses, sem DECH ativa e sem } \\
\text { imunossupressão) }\end{array}$ \\
\hline $\begin{array}{l}\text { Febre amarela } \\
\text { (Vírus vivos atenuados) }\end{array}$ & $\begin{array}{l}\text { Dados limitados sobre eficácia e segurança }{ }^{1} \\
\text { Considerar o uso em pacientes vivendo em } \\
\text { áreas endêmicas ou viajando para tais áreas }\end{array}$ & $\begin{array}{l}\text { EIII (<24 meses pós-TCTH, ou DECH ativa } \\
\text { ou recebendo imunossupressão) } \\
\text { CIII ( }>24 \text { meses, sem DECH ativa e sem } \\
\text { imunossupressão) }\end{array}$ \\
\hline Raiva $^{2}$ & $\begin{array}{l}\text { Pode ser usada em receptores de TCTH com risco } \\
\text { ocupacional para raiva. Vacinação pré-exposição } \\
\text { pode ser iniciada após o primeiro ano pós-transplante. } \\
\text { Já a administração da imunoglobulina antirrábica } \\
\text { pós-exposição pode ser administrada a qualquer } \\
\text { momento pós-TCTH se houver indicação }{ }^{144}\end{array}$ & CIII \\
\hline Papilomavírus humanos & $\begin{array}{l}\text { Seguir recomendação da população em geral } \\
\text { Não há dados com relação ao tempo pós-transplante } \\
\text { quando a vacina deve ser iniciada }\end{array}$ & CIII \\
\hline $\begin{array}{l}\text { Vacina oral contra a } \\
\text { poliomielite } \\
\text { (vivos atenuados) }\end{array}$ & $\begin{array}{l}\text { Contraindicada para receptores de TCTH, } \\
\text { que devem utilizar a vacina inativada }\end{array}$ & EIII \\
\hline $\begin{array}{l}\text { Vacina de influenza } \\
\text { intranasal (vivos atenuados) }\end{array}$ & $\begin{array}{l}\text { Não há dados sobre segurança e efetividade. } \\
\text { A vacina inativada deve ser utilizada }\end{array}$ & EIII) \\
\hline Cólera & $\begin{array}{l}\text { Não há dados sobre segurança e efetividade em } \\
\text { receptores de TCTH. }\end{array}$ & DIII \\
\hline $\begin{array}{l}\text { Febre tifoide oral (vivos } \\
\text { atenuados) }\end{array}$ & $\begin{array}{l}\text { Não há dados sobre segurança e efetividade em } \\
\text { receptores de TCTH. }\end{array}$ & EIII \\
\hline Febre tifoide (intramuscular) & $\begin{array}{l}\text { Não há dados sobre segurança e efetividade em } \\
\text { receptores de TCTH. }\end{array}$ & DIII \\
\hline Rotavírus & $\begin{array}{l}\text { Deve ser dada antes de } 12 \text { semanas de idade } \\
\text { para ser segura. }\end{array}$ & EIII \\
\hline $\begin{array}{l}\text { Vacina antizoster (vivos } \\
\text { atenuados) }\end{array}$ & $\begin{array}{l}\text { Não há dados sobre segurança e efetividade em } \\
\text { receptores de TCTH. }\end{array}$ & ElII \\
\hline
\end{tabular}

${ }_{1}^{1}$ Mais de vinte receptores de TCTH foram vacinados sem relatos de eventos adversos

${ }^{2}$ Vacinação pós-exposição inclui cinco doses da vacina administrada nos dias $0,3,7,14$ e 28 pós-exposição

Vacinação de familiares, contactuantes e profissionais de saúde cuidando de receptores de TCTH (Vacinas disponibilizadas nos CRIEs)

\begin{tabular}{|c|c|c|}
\hline Vacina & Recomendações & Nível de vidência \\
\hline Hepatite A & Doadores de candidatos a TCTH, cadastrados em programas de transplantes. & BIII \\
\hline \multirow[t]{2}{*}{$\begin{array}{l}\text { Vacina inativada contra influenza } \\
\text { NOTA: vacina de influenza } \\
\text { Intranasal é contraindicada (EIII) }\end{array}$} & $\begin{array}{l}\text { Contactuantes domiciliares devem receber a vacina anualmente, iniciando na } \\
\text { temporada anterior ao transplante e enquanto o receptor de TCTH estiver } \\
\text { recebendo imunossupressores }\end{array}$ & All \\
\hline & Profissionais de saúde devem receber a vacina anualmente & Al \\
\hline Poliomielite ${ }^{\mathrm{b}}$ & $\begin{array}{l}\text { Crianças em contato domiciliar ou hospitalar com receptor de TCTH, } \\
\text { que necessitem receber a vacina contra a poliomielite, devem receber } \\
\text { a vacina inativada (Salk) }\end{array}$ & All \\
\hline Rotavírus & $\begin{array}{l}\text { Vacinação não é contraindicada em contactuantes de receptores de TCTH } \\
\text { Seguir a orientação do programa nacional de vacinação }\end{array}$ & CIII \\
\hline $\begin{array}{l}\text { VZVe } \\
\text { (vírus vivos atenuados) }\end{array}$ & $\begin{array}{l}\text { Profissionais de saúde, pessoas e familiares suscetíveis à doença e } \\
\text { imunocompetentes que estejam em convívio domiciliar ou hospitalar com } \\
\text { receptores de TCTH } \\
\text { Doadores de TCTH, antes da doação das células-tronco hematopoéticas }\end{array}$ & CIII \\
\hline
\end{tabular}

Notas: a) Em caso de surto de influenza, profissionais de saúde e contactuantes domiciliares devem receber quimioprofilaxia de acordo com a cepa identificada $(\mathrm{BI})$, caso o surto ocorra antes do tempo necessário para a resposta imunológica à vacina. Se o surto ocorrer por uma cepa viral não incluída na constituição da vacina naquele ano a quimioprofilaxia deve ser prolongada até o fim da circulação dos vírus influenza (BIII). b) Vacina antipólio oral pode se transmitir de pessoa a pessoa, portanto seu uso é contraindicado em contatuantes de domiciliares de receptores de TCTH 
Anexo 1: Recomendações quanto ao controle de infecção em centros de TCTH.

Recomendação

\section{Ventilação}

Normas técnicas devem ser seguidas para planejamento arquitetônico e ventilação do quarto ${ }^{145}$

Evitar o acesso de pássaros aos dutos de ventilação

Pacientes submetidos à TCTH alogênico devem permanecer em quartos com taxa de filtração do ar

$>12$ trocas por hora e filtros HEPA

Para pacientes submetidos a TCTH autólogo de alto risco, com tempo de neutropenia prolongado, considerar o uso de filtros HEPA

No caso do uso de filtro HEPA portátil, este deve ser colocado no centro do quarto

CIII

BIII

Fluxo laminar não é necessário e, se disponível, seu uso é opcional

Quartos devem ter fluxo de ar direto, entrando ar de um lado e saindo pelo lado oposto

Cll

BIII

Quartos devem ser bem vedados (ao redor das janelas, portas e parte elétrica)

BIII

Para manter pressão positiva os quartos devem ter uma diferença de pressão (>2.5 Pa)

em relação ao corredor ou ante sala

\section{Construção e Reforma}

Diretrizes a respeito de medidas de controle de infecção durante construções devem ser seguidas ${ }^{146}$

Pacientes submetidos a TCTH devem evitar áreas de construção e reforma, assim como profissionais de saúde e visitantes dos centros de TCTH

Alll

Durante construção e reforma, medidas de controle de dispersão de poeira devem ser intensificadas:

- estabelecer fluxo adequado de entrada/saída dos trabalhadores da área em construção

- trocar de roupa e disponibilizar panos úmidos para umidificar os sapatos antes de sair desta área

- proporcionar a vedação adequada da área, uso de paredes provisórias

- manter as saídas de emergência vedadas ou com uso de filtros (HEPA portátil)

- o transporte de entulho deve ocorrer de forma planejada, em carros fechados ou em sacos lacrados

- limpeza frequente da área próxima à construção

Para implementar estas medidas, comitês de planejamento de construção e reforma devem ser multidisciplinares e incluir representantes do controle de infecção

A abertura ou fechamento de portas ou de outras barreiras que levem à entrada de poeira na área de cuidado dos pacientes deve ser minimizada

Utilizar entradas, saídas, corredores e elevadores específicos para a construção

Após construção ou reforma, a área deve ser limpa antes da utilização do paciente

\section{Limpeza}

Centros de TCTH devem ser limpos seguindo o protocolo descrito pela comissão de controle de infecção hospitalar $(\mathrm{CClH})$ e serviço de higiene

Pacientes não devem ser expostos a atividades que levem a aerosolização de esporos fúngicos, como o uso de aspirador de pó

Piso do quarto e do centro de TCTH não deve ter carpete

Pisos, tetos, rodapés, mobiliário e outros materiais devem ter superfície lisa, não porosa e passíveis de limpeza

\section{Isolamento e precauções}

Centros de TCTH devem seguir diretrizes para prevenção das IRAs ${ }^{60}$ 
Anexo 1: Recomendações quanto ao controle de infecção em centros de TCTH (continuação)

Recomendação

Nível de evidência

Quando houver risco de contato com sangue ou secreções o uso adequado do equipamento de uso individual (EPIs) inclui a utilização de avental de manga longa, luvas, máscara cirúrgica e óculos de proteção

Quando apropriado, precauções de contato, gotículas e/ou aerossóis devem ser instituídas

\section{Higiene das mãos}

Todos os profissionais de saúde e outras pessoas que entrem nos quartos dos pacientes devem higienizar as mãos conforme normatização específica ${ }^{147,148}$

Solução antisséptica (sabão antisséptico ou gel a base de álcool) deve ser utilizada para higiene das mãos

Pacientes submetidos a TCTH devem manter boa higiene das mãos

O uso adequado das luvas deve ser encorajado, dentro do escopo das precauções padrão; usar luvas quando for previsto o contato com sangue, secreções ou outros materiais potencialmente contaminados, além do contato com mucosas ou pele não íntegra

O uso das luvas não suplanta a necessidade da higiene das mãos e esta deve ser realizada ao colocar e retirar as luvas

Luvas devem ser trocadas entre o manejo de vários pacientes e também entre o cuidado de uma região contaminada para região limpa

Unhas postiças não devem ser utilizadas

Unhas devem ser mantidas curtas e limpas

Anéis e outros itens utilizados nas mãos podem facilitar o crescimento de microorganismos patogênicos e devem ser evitados

\section{Plantas e brinquedos}

Plantas e flores desidratadas ou frescas não devem ser permitidas nos quartos ou corredores dos pacientes submetidos a TCTH

Brinquedotecas para crianças submetidas a TCTH devem ser limpas conforme recomendação da CCIH e serviço de higiene

Somente brinquedos e jogos que possam ser limpos podem ser liberados em centros de transplante

Brinquedos de pano e pelúcia devem ser evitados exceto se houver disponibilidade de serem lavados em máquina de lavar com ciclos de água quente

Brinquedos de plástico rígido devem ser lavados com água e sabão ou solução detergente, e imersos em solução desinfetante ou outro método de desinfecção

Crianças e bebês que levem os brinquedos a boca não devem compartilhar seus brinquedos

Brinquedos de banho que retenham água devem ser evitados

DII

Itens de terapia ocupacional e fisioterapia devem ser limpos e desinfetados conforme a rotina estabelecia pela $\mathrm{CCIH}$

\section{Profissionais de saúde}

Centros de TCTH devem redigir normatizações de vacinação e saúde ocupacional ${ }^{149}$

Promover vacinação dos profissionais de saúde para sarampo, caxumba, rubéola, hepatite B e, especialmente, influenza e varicela

Profissionais de saúde com doenças transmissíveis por aerossóis, gotículas ou contato direto devem ser afastadas do contato com os pacientes

Políticas de afastamento do trabalho devem ser desenhadas para facilitar o relato do profissional de saúde quanto às doenças e exposições 
Anexo 1: Recomendações quanto ao controle de infecção em centros de TCTH (continuação)

Recomendação

Nível de evidência

\section{Visitantes}

Todos os visitantes devem ser avaliados por profissionais de saúde treinados quanto a exposição a agentes infecciosos ou a presença de possíveis infecções (especialmente as virais) Visitantes com doenças transmissíveis por contato não devem ser liberados para o contato com pacientes TCTH

BII

Não há limite mínimo de idade para visitantes. No entanto todos os visitantes devem ter capacidade de entender e seguir as normas de higiene das mãos e os procedimentos de isolamento

O número de visitantes (por vez) deve ser restrito a um número que permita avaliação e educação apropriadas

\section{Cuidados com boca e pele do paciente}

Pacientes submetidos a TCTH devem tomar banho diariamente com sabonete suave

Durante neutropenia, sítios potenciais de infecção devem ser examinados diariamente (períneo, inserção de cateter, etc... )

Mulheres menstruadas não devem usar absorvente interno durante imunossupressão

DIII

Termômetros retais, enemas, supositórios e exames retais devem ser evitados

DIII

Boa higiene da boca e dentes deve ser mantida

Alll

Avaliação dentária e o tratamento relevante deve ser realizado até 10-14 dias antes do início do condicionamento

AllI

Supervisão rotineira dos dentes é recomendada

Durante mucosite, aparelhos fixos (de dentes) não devem ser utilizados

Retirada do aparelho fixo deve ser coordenada com o dentista do paciente

Dentaduras podem ser utilizadas durante neutropenia dependendo do grau de integridade da mucosa e da habilidade do paciente de manter boa higiene oral

Alll

BIII

Prevenção de infecção relacionada ao cateter

Centros de TCTH devem implementar diretrizes para prevenção de infecções relacionadas ao cateter ${ }^{150}$

Alll

A barreira máxima estéril (BME), avental de manga longa estéril, luvas estéreis, gorro, máscara e campo estéril grande cobrindo o paciente devem ser utilizados na inserção do cateter venoso central (CVC) ${ }^{151}$

Uso preferencial de clorexidina para inserção e curativos de CVC ${ }^{151,152}$

Contato com água na inserção do CVC deve ser evitado

BIII

Pacientes submetidos a TCTH devem cobrir o cateter durante o banho

Pacientes e cuidadores devem receber educação apropriada quanto aos cuidados do cateter

\section{Vigilância de Infecções}

Centros de TCTH devem seguir normatizações quanto ao uso racional de antimicrobianos, vigilância de microorganismos hospitalares e susceptibilidade

Na ausência de surtos de infecção, a vigilância de rotina do ambiente (superfícies, mobiliários) não é recomendada

DII

Amostras de ar, dos dutos de ventilação e filtros devem ser realizadas por ocasião de construção ou reforma ou se a vigilância clínica indicar aumento das infecções por fungos filamentosos

CIII

$\mathrm{Na}$ ausência de surtos, a coleta rotineira de ar e água (para avaliar presença de fungos filamentosos e Legionella ssp) deve ser avaliada em conjunto com a $\mathrm{CClH}$, a depender dos recursos disponíveis (medida pró-ativa de prevenção destas infecções), ou então realizar as culturas após documentação de casos clínicos.

Alll

Centros de TCTH devem realizar vigilância epidemiológica das IRAs
AIII 


\begin{abstract}
Infectious complications following stem cell transplantation are frequent and associated with high morbidity and mortality. Several factors related to the transplant procedure, such as type of transplant, the source of stem cells, the utilization of alternative donors are important determinants of the immune status of the host, and impact on the risk of infection. In this section we will discuss the different approaches for monitoring patients at risk and diagnosing and treating infectious complications in three time periods: before transplant, during neutropenia, and after engraftment. Rev. Bras. Hematol. Hemoter. 2010;32(Supl. 1):140-162.
\end{abstract}

Key words: Stem cell transplant; neutropenia; infection; complication.

\section{Referências Bibliográficas}

1. Wingard JR. Opportunistic infections after blood and marrow transplantation. Transpl Infect Dis. 1999;1(1):3-20.

2. Wingard JR, Vogelsang GB, Deeg HJ. Stem cell transplantation: supportive care and long-term complications. Hematology Am Soc Hematol Educ Program. 2002;422-44.

3. AABB. Standards for cellular therapy products services. 3rd ed. Bethesda, MD: 2007.

4. Food and Drug Administration. Guidance for industry: Elegibility determination for donor of human cells, tissues, and cellular-andtissue-based products (HCT/Ps). Washington, DC: 2007.

5. National Marrow Donor Program. National Marrow Donor Program Standards. 19 ${ }^{\text {th }}$ ed. Minneapolis: 2004.

6. European Commission. Commission Directives 2006/17/EC. 2009. Report No.: L 38.

7. US National Archives and Records Administration. Donor Elegibility. Washington, DC; 2004. Report No.: 21 CFR, Part 1271.

8. Kotton CN. Zoonoses in solid-organ and hematopoietic stem cell transplant recipients. Clin Infect Dis. 2007;44(6):857-66.

9. Ljungman P, Perez-Bercoff L, Jonsson J, Avetisyan G, Sparrelid E, Aschan J, et al. Risk factors for the development of cytomegalovirus disease after allogeneic stem cell transplantation. Haematologica. 2006;91(1):78-83.

10. Matsuo Y, Takeishi S, Miyamoto T, Nonami A, Kikushige Y, Kunisaki Y, et al. Toxoplasmosis encephalitis following severe graft-vs.-host disease after allogeneic hematopoietic stem cell transplantation: 17 yr experience in Fukuoka BMT group. Eur J Haematol. 2007;79(4):317-21.

11. Nichols WG, Corey L, Gooley T, Davis C, Boeckh M. High risk of death due to bacterial and fungal infection among cytomegalovirus (CMV)-seronegative recipients of stem cell transplants from seropositive donors: evidence for indirect effects of primary CMV infection. J Infect Dis. 2002;185(3):273-82.

12. Slavin MA, Meyers JD, Remington JS, Hackman RC. Toxoplasma gondii infection in marrow transplant recipients: a 20 year experience. Bone Marrow Transplant. 1994;13(5):549-57.

13. Centers for Disase Control and Prevention. Chagas disease after organ transplantation - United States, 2001. 2001. Report $N^{\circ} 51$.

14. Centers for Disase Control and Prevention. Blood donor screening for chagas disease - United States, 2006-2007. 2007. Report $\mathrm{N}^{\mathrm{o}} 56$.

15. Dodd RY. Transmission of parasites by blood transfusion. Vox Sang 1998;74 Suppl 2:161-3.
16. Leiby DA, Lenes BA, Tibbals MA, Tames-Olmedo MT. Prospective evaluation of a patient with Trypanosoma cruzi infection transmitted by transfusion. N Engl J Med. 1999;341(16):1237-9.

17. Aljurf M, Gyger M, Alrajhi A, Sahovic E, Chaudhri N, Musa M, et al. Mycobacterium tuberculosis infection in allogeneic bone marrow transplantation patients. Bone Marrow Transplant. 1999;24(5): $551-4$.

18. Tavil B, Gulhan B, Ozcelik U, Cetin M, Tezcan I, Tuncer M, et al. Tuberculin skin test positivity in pediatric allogeneic BMT recipients and donors in Turkey. Pediatr Transplant. 2007;11(4):414-8.

19. Lefrere F, Besson C, Datry A, Chaibi P, Leblond V, Binet JL, et al. Transmission of Plasmodium falciparum by allogeneic bone marrow transplantation. Bone Marrow Transplant. 1996;18(2):473-4.

20. Fries BC, Riddell SR, Kim HW, Corey L, Dahlgren C, Woolfrey A, et al. Cytomegalovirus disease before hematopoietic cell transplantation as a risk for complications after transplantation. Biol Blood Marrow Transplant. 2005;11(2):136-48.

21. Bowden RA, Slichter SJ, Sayers M, Weisdorf D, Cays M, Schoch G, et al. A comparison of filtered leukocyte-reduced and cytomegalovirus (CMV) seronegative blood products for the prevention of transfusion-associated CMV infection after marrow transplant. Blood. 1995;86(9):3598-603.

22. Ljungman P, Brand R, Einsele H, Frassoni F, Niederwieser D, Cordonnier C. Donor CMV serologic status and outcome of CMV-seropositive recipients after unrelated donor stem cell transplantation: an EBMT megafile analysis. Blood. 2003;102 (13):4255-60.

23. Lucas KG, Filo F, Heilman DK, Lee CH, Emanuel DJ. Semiquantitative Epstein-Barr virus polymerase chain reaction analysis of peripheral blood from organ transplant patients and risk for the development of lymphoproliferative disease. Blood. 1998;92 (10):3977-8.

24. Omar H, Hagglund H, Gustafsson-Jernberg A, Leblanc K, Mattsson $\mathrm{J}$, Remberger $\mathrm{M}$, et al. Targeted monitoring of patients at high risk of post-transplant lymphoproliferative disease by quantitative Epstein-Barr virus polymerase chain reaction. Transpl Infect Dis. 2009;11(5):393-9.

25. Styczynski J, Reusser P, Einsele H, de la CR, Cordonnier C, Ward $\mathrm{KN}$, et al. Management of HSV, VZV and EBV infections in patients with hematological malignancies and after SCT: guidelines from the Second European Conference on Infections in Leukemia. Bone Marrow Transplant. 2009;43(10):757-70.

26. van Esser JW, van der HB, Meijer E, Niesters HG, Trenschel R, Thijsen SF, et al. Epstein-Barr virus (EBV) reactivation is a frequent event after allogeneic stem cell transplantation (SCT) and quantitatively predicts EBV-lymphoproliferative disease following T-cell--depleted SCT. Blood. 2001;98(4):972-8.

27. Gerritsen EJ, Stam ED, Hermans J, van den BH, Haraldsson A, van Tol MJ, et al. Risk factors for developing EBV-related B cell lymphoproliferative disorders (BLPD) after non-HLA-identical BMT in children. Bone Marrow Transplant. 1996;18(2):377-82.

28. Holmes CN. Predictive value of a history of varicella infection. Can Fam Physician. 2005;51:60-5.

29. Josephson A, Gombert ME. Airborne transmission of nosocomial varicella from localized zoster. J Infect Dis. 1988;158(1):238-41.

30. Boeckh M, Kim HW, Flowers ME, Meyers JD, Bowden RA. Longterm acyclovir for prevention of varicella zoster virus disease after allogeneic hematopoietic cell transplantation - a randomized doubleblind placebo-controlled study. Blood. 2006;107(5):1800-5.

31. Erard V, Guthrie KA, Varley C, Heugel J, Wald A, Flowers ME, et al. One-year acyclovir prophylaxis for preventing varicella-zoster virus disease after hematopoietic cell transplantation: no evidence of rebound varicella-zoster virus disease after drug discontinuation. Blood. 2007;110(8):3071-7. 
32. Liang R. How I treat and monitor viral hepatitis B infection in patients receiving intensive immunosuppressive therapies or undergoing hematopoietic stem cell transplantation. Blood. 2009; 113(14):3147-53.

33. Lau GK, Lie A, Liang R. Prophylactic lamivudine therapy for hepatitis B patients undergoing immunosuppressive therapy. Blood. 2002;100(8):3054

34. Hui CK, Lie A, Au WY, Leung YH, Ma SY, Cheung WW, et al. A long-term follow-up study on hepatitis B surface antigen-positive patients undergoing allogeneic hematopoietic stem cell transplantation. Blood. 2005;106(2):464-9.

35. Carreras E. Risk assessment in haematopoietic stem cell transplantation: the liver as a risk factor. Best Pract Res Clin Haematol. 2007;20(2):231-46

36. Peffault de LR, Levy V, Asselah T, Marcellin P, Scieux C, Ades L, et al. Long-term outcome of hepatitis $\mathrm{C}$ infection after bone marrow transplantation. Blood. 2004;103(5):1618-24.

37. Locasciulli A, Alberti A. Hepatitis C virus serum markers and liver disease in children with leukemia. Leuk Lymphoma. 1995;17(34):245-9.

38. Shuhart MC, Myerson D, Childs BH, Fingeroth JD, Perry JJ, Snyder DS, et al. Marrow transplantation from hepatitis $\mathrm{C}$ virus seropositive donors: transmission rate and clínical course. Blood. 1994;84(9):3229-35.

39. Surapaneni SN, Hari P, Knox J, Daniel J, Saeian K. Suppressive anti-HCV therapy for prevention of donor to recipient transmission in stem cell transplantation. Am J Gastroenterol. 2007;102(2):449-51.

40. Strasser SI, Myerson D, Spurgeon CL, Sullivan KM, Storer B, Schoch HG, et al. Hepatitis $\mathrm{C}$ virus infection and bone marrow transplantation: a cohort study with 10-year follow-up. Hepatology. 1999;29(6):1893-9.

41. Targeted tuberculin testing and treatment of latent tuberculosis infection. American Thoracic Society. MMWR Recomm Rep. 2000;49(RR-6):1-51.

42. Derouin F, Devergie A, Auber P, Gluckman E, Beauvais B, Garin YJ, et al. Toxoplasmosis in bone marrow-transplant recipients: report of seven cases and review. Clin Infect Dis. 1992;15(2):267-70.

43. Martino R, Maertens J, Bretagne S, Rovira M, Deconinck E, Ullmann AJ, et al. Toxoplasmosis after hematopoietic stem cell transplantation. Clin Infect Dis. 2000;31(5):1188-95.

44. Martino R, Cordonnier C. Toxoplasmosis following allogeneic hematopoietic stem cell transplantation. Bone Marrow Transplant. 2003;31(7):617-8

45. Small TN, Leung L, Stiles J, Kiehn TE, Malak SA, OReilly RJ, et al. Disseminated toxoplasmosis following $\mathrm{T}$ cell-depleted related and unrelated bone marrow transplantation. Bone Marrow Transplant. 2000;25(9):969-73.

46. Schaffel R, Portugal R, Maiolino A, Nucci M. Strongyloidiasis pre and post autologous peripheral blood stem cell transplantation. Bone Marrow Transplant. 2004;33(1):117.

47. Nucci M, Portugal R, Pulcheri W, Spector N, Ferreira SB, de Castro $\mathrm{MB}$, et al. Strongyloidiasis in patients with hematologic malignancies. Clin Infect Dis. 1995;21(3):675-7.

48. Portugal R, Schaffel R, Almeida L, Spector N, Nucci M. Thiabendazole for the prophylaxis of strongyloidiasis in immunosuppressed patients with hematological diseases: a randomized double-blind placebo-controlled study. Haematologica. 2002;87(6):663-4

49. Schaffel R, Nucci M, Portugal R, Castro MB, Ferreira SB, Almeida $\mathrm{L}$, et al. Thiabendazole for the treatment of strongyloidiasis in patients with hematologic malignancies. Clin Infect Dis. 2000; 31(3):821-2.
50. Keiser PB, Nutman TB. Strongyloides stercoralis in the Immunocompromised Population. Clin Microbiol Rev. 2004;7(1): 208-17.

51. Dictar M, Sinagra A, Veron MT, Luna C, Dengra C, De RA, et al. Recipients and donors of bone marrow transplants suffering from Chagas disease: management and preemptive therapy of parasitemia. Bone Marrow Transplant. 1998;21(4):391-3.

52. Altclas J, Sinagra A, Jaimovich G, Salgueira C, Luna C, Requejo A, et al. Reactivation of chronic Chagas disease following allogeneic bone marrow transplantation and successful pre-emptive therapy with benznidazole. Transpl Infect Dis. 1999;1(2):135-7.

53. Altclas J, Sinagra A, Dictar M, Luna C, Veron MT, De Rissio AM, et al. Chagas disease in bone marrow transplantation: an approach to preemptive therapy. Bone Marrow Transplant. 2005;36(2):123-9.

54. Rupp M. Hematopoietic Stem Cell Transplantation. In: Association for Professional in Infection Control Epidemiology - APIC, editor. Text of Infection Control and Epidemiology. 2005.

55. Sullivan KM, Dykewicz CA, Longworth DL, Boeckh M, Baden LR, Rubin RH, et al. Preventing opportunistic infections after hematopoietic stem cell transplantation: the Centers for Disease Control and Prevention, Infectious Diseases Society of America, and American Society for Blood and Marrow Transplantation Practice Guidelines and beyond. Hematology Am Soc Hematol Educ Program 2001;392-421.

56. Schlesinger A, Paul M, Gafter-Gvili A, Rubinovitch B, Leibovici L. Infection-control interventions for cancer patients after chemotherapy: a systematic review and meta-analysis. Lancet Infect Dis. 2009;9(2):97-107.

57. Harris AD, McGregor JC, Furuno JP. What infection control interventions should be undertaken to control multidrugresistant gram-negative bacteria? Clin Infect Dis. 2006;43 Suppl 2:S57-S61.

58. Pittet D. Improving compliance with hand hygiene in hospitals. Infect Control Hosp Epidemiol. 2000;21(6):381-6.

59. Trick WE, Vernon MO, Welbel SF, Demarais P, Hayden MK, Weinstein RA. Multicenter intervention program to increase adherence to hand hygiene recommendations and glove use and to reduce the incidence of antimicrobial resistance. Infect Control Hosp Epidemiol. 2007;28(1):42-9.

60. Siegel JD, Rhinehart E, Jackson M, Chiarello L. 2007 Guideline for Isolation Precautions: Preventing Transmission of Infectious Agents in Health Care Settings. Am J Infect Control. 2007;35(10 Suppl 2):S65-164.

61. Tablan OC, Anderson LJ, Besser R, Bridges C, Hajjeh R. Guidelines for preventing health-care - associated pneumonia, 2003: recommendations of $\mathrm{CDC}$ and the Healthcare Infection Control Practices Advisory Committee. MMWR Recomm Rep. 2004 26; 53(RR-3):1-36.

62. Davey P, Brown E, Fenelon L, Finch R, Gould I, Holmes A, et al. Systematic review of antimicrobial drug prescribing in hospitals. Emerg Infect Dis. 2006;12(2):211-6.

63. Siegel JD, Rhinehart E, Jackson M, Chiarello L. Management of multidrug-resistant organisms in health care settings, 2006. Am J Infect Control. 2007;35(10 Suppl 2):S165-S193.

64. Bucaneve G, Micozzi A, Menichetti F, Martino P, Dionisi MS, Martinelli G, et al. Levofloxacin to prevent bacterial infection in patients with cancer and neutropenia. N Eng1 J Med. 2005;353 (10):977-87.

65. Cruciani M, Rampazzo R, Malena M, Lazzarini L, Todeschini G, Messori A, et al. Prophylaxis with fluoroquinolones for bacterial infections in neutropenic patients: a meta-analysis. Clin Infect Dis. 1996;23(4):795-805.

66. Gafter-Gvili A, Fraser A, Paul M, Leibovici L. Meta-analysis: 
antibiotic prophylaxis reduces mortality in neutropenic patients. Ann Intern Med. 2005;142(12 Pt 1):979-95.

67. Gafter-Gvili A, Paul M, Fraser A, Leibovici L. Effect of quinolone prophylaxis in afebrile neutropenic patients on microbial resistance: systematic review and meta-analysis. J Antimicrob Chemother. 2007;59(1):5-22

68. Cruciani M, Malena M, Bosco O, Nardi S, Serpelloni G, Mengoli C. Reappraisal with meta-analysis of the addition of Gram-positive prophylaxis to fluoroquinolone in neutropenic patients. J Clin Oncol. 2003;21(22):4127-37.

69. Saral R, Burns WH, Laskin OL, Santos GW, Lietman PS. Acyclovir prophylaxis of herpes-simplex-virus infections. N Engl J Med. 1981;305(2):63-7.

70. Wade JC, Day LM, Crowley JJ, Meyers JD. Recurrent infection with herpes simplex virus after marrow transplantation: role of the specific immune response and acyclovir treatment. J Infect Dis. 1984;149(5):750-6.

71. Ghosh S, Champlin RE, Englund J, Giralt SA, Rolston K, Raad I, et $a l$. Respiratory syncytial virus upper respiratory tract illnesses in adult blood and marrow transplant recipients: combination therapy with aerosolized ribavirin and intravenous immunoglobulin. Bone Marrow Transplant. 2000;25(7):751-5.

72. Eisen D, Essell J, Broun ER, Sigmund D, DeVoe M. Clinical utility of oral valacyclovir compared with oral acyclovir for the prevention of herpes simplex virus mucositis following autologous bone marrow transplantation or stem cell rescue therapy. Bone Marrow Transplant. 2003;31(1):51-5.

73. Peck AJ, Corey L, Boeckh M. Pretransplantation respiratory syncytial virus infection: impact of a strategy to delay transplantation. Clin Infect Dis. 2004;39(5):673-80.

74. Barnes PD, Marr KA. Risks, diagnosis and outcomes of invasive fungal infections in haematopoietic stem cell transplant recipients. Br J Haematol. 2007;139(4):519-31.

75. Slavin MA, Osborne B, Adams R, Levenstein MJ, Schoch HG, Feldman $\mathrm{AR}$, et al. Efficacy and safety of fluconazole prophylaxis for fungal infections after marrow transplantation--a prospective, randomized, double-blind study. J Infect Dis. 1995;171(6):1545-52.

76. Goodman JL, Winston DJ, Greenfield RA, Chandrasekar PH, Fox $\mathrm{B}$, Kaizer H, et al. A controlled trial of fluconazole to prevent fungal infections in patients undergoing bone marrow transplantation. N Engl J Med. 1992;326(13):845-51.

77. Marr KA, Seidel K, Slavin MA, Bowden RA, Schoch HG, Flowers $\mathrm{ME}$, et al. Prolonged fluconazole prophylaxis is associated with persistent protection against candidiasis-related death in allogeneic marrow transplant recipients: long-term follow-up of a randomized, placebo-controlled trial. Blood. 2000;96(6):2055-61.

78. van Burik JA, Ratanatharathorn V, Stepan DE, Miller CB, Lipton $\mathrm{JH}$, Vesole $\mathrm{DH}$, et al. Micafungin versus fluconazole for prophylaxis against invasive fungal infections during neutropenia in patients undergoing hematopoietic stem cell transplantation. Clin Infect Dis. 2004;39(10):1407-16.

79. Oren I, Rowe JM, Sprecher H, Tamir A, Benyamini N, Akria L, et al. A prospective randomized trial of itraconazole vs fluconazole for the prevention of fungal infections in patients with acute leukemia and hematopoietic stem cell transplant recipients. Bone Marrow Transplant. 2006;38(2):127-34.

80. Wingard JR, Carter SL, Walsh TJ, et al. Results of a randomized, double-blind trial of fluconazole vs. voriconazole for the prevention of invasive fungal infections in 600 allogeneic blood and marrow transplant petients. Blood. 2007;110:55a.

81. Cornely OA, Maertens J, Winston DJ, Perfect J, Ullmann AJ, Walsh $\mathrm{TJ}$, et al. Posaconazole vs. fluconazole or itraconazole prophylaxis in patients with neutropenia. N Engl J Med. 2007; 356(4):348-59.
82. Cordonnier C, Herbrecht R, Buzyn A, Leverger G, Leclercq R, Nitenberg G, et al. Risk factors for Gram-negative bacterial infections in febrile neutropenia. Haematologica. 2005;90 (8): 1102-9.

83. Klastersky J. Management of fever in neutropenic patients with different risks of complications. Clin Infect Dis. 2004;39 Suppl $1: \mathrm{S} 32-\mathrm{S} 37$.

84. Aoun M. Empiric therapy for febrile neutropenia: what are the choices? Expert Rev Anti Infect Ther. 2007;5(3):507-15.

85. Bow EJ, Rotstein C, Noskin GA, Laverdiere M, Schwarer AP, Segal $\mathrm{BH}$, et al. A randomized, open-label, multicenter comparative study of the efficacy and safety of piperacillin-tazobactam and cefepime for the empirical treatment of febrile neutropenic episodes in patients with hematologic malignancies. Clin Infect Dis. 2006;43(4):447-59.

86. Paul M, Yahav D, Fraser A, Leibovici L. Empirical antibiotic monotherapy for febrile neutropenia: systematic review and metaanalysis of randomized controlled trials. J Antimicrob Chemother. 2006;57(2):176-89.

87. Paul M, Soares-Weiser K, Grozinsky S, Leibovici L. Beta-lactam versus beta-lactam-aminoglycoside combination therapy in cancer patients with neutropaenia. Cochrane Database Syst Rev. 2003; (3):CD003038.

88. Paul M, Soares-Weiser K, Leibovici L. Beta lactam monotherapy versus beta lactam-aminoglycoside combination therapy for fever with neutropenia: systematic review and meta-analysis. BMJ. 2003; 326(7399):1111.

89. Paul M, uri-Silbiger I, Soares-Weiser K, Leibovici L. Beta lactam monotherapy versus beta lactam-aminoglycoside combination therapy for sepsis in immunocompetent patients: systematic review and meta-analysis of randomised trials. BMJ. 2004;328(7441):668.

90. Paul M, Borok S, Fraser A, Vidal L, Leibovici L. Empirical antibiotics against Gram-positive infections for febrile neutropenia: systematic review and meta-analysis of randomized controlled trials. J Antimicrob Chemother. 2005;55(4):436-44.

91. Cometta A, Kern WV, De BR, Paesmans M, Vandenbergh M, Crokaert F, et al. Vancomycin versus placebo for treating persistent fever in patients with neutropenic cancer receiving piperacillintazobactam monotherapy. Clin Infect Dis. 2003;37(3):382-9.

92. Bow EJ, Loewen R, Vaughan D. Reduced requirement for antibiotic therapy targeting gram-negative organisms in febrile, neutropenic patients with cancer who are receiving antibacterial chemoprophylaxis with oral quinolones. Clin Infect Dis. 1995;20 (4):907-12.

93. Hughes WT, Armstrong D, Bodey GP, Bow EJ, Brown AE, Calandra T, et al. 2002 guidelines for the use of antimicrobial agents in neutropenic patients with cancer. Clin Infect Dis. 2002; 34(6):730-51.

94. From the Immunocompromised Host Society. The design, analysis, and reporting of clínical trials on the empirical antibiotic management of the neutropenic patient. Report of a consensus panel. J Infect Dis. 1990;161(3):397-401.

95. Feld R, Paesmans M, Freifeld AG, Klastersky J, Pizzo PA, Rolston $\mathrm{KV}$, et al. Methodology for clínical trials involving patients with cancer who have febrile neutropenia: updated guidelines of the Immunocompromised Host Society/Multinational Association for Supportive Care in Cancer, with emphasis on outpatient studies. Clin Infect Dis. 2002;35(12):1463-8.

96. Portugal RD, Garnica M, Nucci M. Index to predict invasive mold infection in high-risk neutropenic patients based on the area over the neutrophil curve. J Clin Oncol. 2009;27(23):3849-54.

97. Cordonnier C, Pautas C, Maury S, Vekhoff A, Farhat H, Suarez F, et al. Empirical versus preemptive antifungal therapy for highrisk, febrile, neutropenic patients: a randomized, controlled trial. Clin Infect Dis. 2009;48(8):1042-51. 
98. Maertens J, Theunissen K, Verhoef G, Verschakelen J, Lagrou K, Verbeken E, et al. Galactomannan and computed tomographybased preemptive antifungal therapy in neutropenic patients at high risk for invasive fungal infection: a prospective feasibility study. Clin Infect Dis. 2005;41(9):1242-50.

99. Reboli AC, Rotstein C, Pappas PG, Chapman SW, Kett DH, Kumar $\mathrm{D}$, et al. Anidulafungin versus fluconazole for invasive candidiasis. N Engl J Med. 2007;356(24):2472-82.

100. Walsh TJ, Teppler H, Donowitz GR, Maertens JA, Baden LR, Dmoszynska A, et al. Caspofungin versus liposomal amphotericin B for empirical antifungal therapy in patients with persistent fever and neutropenia. N Engl J Med 2004;351(14):1391-402.

101. Walsh TJ, Finberg RW, Arndt C, Hiemenz J, Schwartz C, Bodensteiner $\mathrm{D}$, et al. Liposomal amphotericin B for empirical therapy in patients with persistent fever and neutropenia. National Institute of Allergy and Infectious Diseases Mycoses Study Group. N Engl J Med. 1999;340(10):764-71.

102. Herbrecht R, Denning DW, Patterson TF, Bennett JE, Greene RE, Oestmann JW, et al. Voriconazole versus amphotericin B for primary therapy of invasive aspergillosis. N Engl J Med. 2002; 347(6):408-15.

103. Mora-Duarte J, Betts R, Rotstein C, Colombo AL, ThompsonMoya L, Smietana J, et al. Comparison of caspofungin and amphotericin B for invasive candidiasis. N Engl J Med. 2002; 347(25):2020-9.

104. Nucci M, Marr KA, Queiroz-Telles F, Martins CA, Trabasso P, Costa $\mathrm{S}$, et al. Fusarium infection in hematopoietic stem cell transplant recipients. Clin Infect Dis. 2004;38(9):1237-42.

105. Nucci M, Anaissie E. Fusarium infections in immunocompromised patients. Clin Microbiol Rev. 2007;20(4):695-704.

106. Wilson DT, Drew RH, Perfect JR. Antifungal therapy for invasive fungal diseases in allogeneic stem cell transplant recipients: An update. Mycopathologia. 2009;168(6):313-27

107. Zerr DM, Corey L, Kim HW, Huang ML, Nguy L, Boeckh M. Clinical outcomes of human herpesvirus 6 reactivation after hematopoietic stem cell transplantation. Clin Infect Dis. 2005; 40(7):932-40.

108. Sashihara J, Tanaka-Taya K, Tanaka S, Amo K, Miyagawa H, Hosoi G, et al. High incidence of human herpesvirus 6 infection with a high viral load in cord blood stem cell transplant recipients. Blood. 2002;100(6):2005-11.

109. Cone RW, Huang ML, Corey L, Zeh J, Ashley R, Bowden R. Human herpesvirus 6 infections after bone marrow transplantation: clínical and virologic manifestations. J Infect Dis. 1999; 179(2):311-8

110. Sullivan KM, Storek J, Kopecky KJ, Jocom J, Longton G, Flowers $\mathrm{M}$, et al. A controlled trial of long-term administration of intravenous immunoglobulin to prevent late infection and chronic graft-vs.-host disease after marrow transplantation: clínical outcome and effect on subsequent immune recovery. Biol Blood Marrow Transplant. 1996;2(1):44-53.

111. Wolff SN, Fay JW, Herzig RH, Greer JP, Dummer S, Brown RA, et al. High-dose weekly intravenous immunoglobulin to prevent infections in patients undergoing autologous bone marrow transplantation or severe myelosuppressive therapy. A study of the American Bone Marrow Transplant Group. Ann Intern Med. 1993;118(12):937-42.

112. Haddad PA, Repka TL, Weisdorf DJ. Penicillin-resistant Streptococcus pneumoniae septic shock and meningitis complicating chronic graft versus host disease: a case report and review of the literature. Am J Med. 2002;113(2):152-5.

113. Jenkins SG, Brown SD, Farrell DJ. Trends in antibacterial resistance among Streptococcus pneumoniae isolated in the USA: update from PROTEKT US Years 1-4. Ann Clin Microbiol Antimicrob 2008;7:1

114. Perez Retortillo JA, Marco F, Richard C, Conde E, Manjon R, Bureo E, et al. Pneumococcal pericarditis with cardiac tamponade in a patient with chronic graft-versus-host disease. Bone Marrow Transplant. 1998;21(3):299-300.

115. Tauro S, Dobie D, Richardson G, Hastings M, Mahendra P. Recurrent penicillin-resistant pneumococcal sepsis after matched unrelated donor (MUD) transplantation for refractory $\mathrm{T}$ cell lymphoma. Bone Marrow Transplant. 2000;26(9):1017-9.

116. Ullmann AJ, Lipton JH, Vesole DH, Chandrasekar P, Langston A, Tarantolo SR, et al. Posaconazole or fluconazole for prophylaxis in severe graft-versus-host disease. N Engl J Med. 2007;356(4): $335-47$.

117. Lilleri D, Gerna G, Furione M, Bernardo ME, Giorgiani G, Telli S, et al. Use of a DNAemia cut-off for monitoring human cytomegalovirus infection reduces the number of preemptively treated children and young adults receiving hematopoietic stemcell transplantation compared with qualitative pp65 antigenemia. Blood. 2007;110(7):2757-60

118. Gerna G, Lilleri D, Baldanti F, Torsellini M, Giorgiani G, Zecca M, et al. Human cytomegalovirus immediate-early mRNAemia versus pp65 antigenemia for guiding pre-emptive therapy in children and young adults undergoing hematopoietic stem cell transplantation: a prospective, randomized, open-label trial. Blood. 2003;101(12):5053-60.

119. Machado CM, Dulley FL, Boas LS, Castelli JB, Macedo MC, Silva $\mathrm{RL}$, et al. CMV pneumonia in allogeneic BMT recipients undergoing early treatment of pre-emptive ganciclovir therapy. Bone Marrow Transplant. 2000;26(4):413-7.

120. Holmberg LA, Boeckh M, Hooper H, Leisenring W, Rowley S, Heimfeld $\mathrm{S}$, et al. Increased incidence of cytomegalovirus disease after autologous CD34-selected peripheral blood stem cell transplantation. Blood. 1999;94(12):4029-35.

121. Machado CM, Menezes RX, Macedo MC, Mendes AV, Boas LS, Castelli JB, et al. Extended antigenemia surveillance and late cytomegalovirus infection after allogeneic BMT. Bone Marrow Transplant. 2001;28(11):1053-9.

122. Boeckh M, Nichols WG, Papanicolaou G, Rubin R, Wingard JR, Zaia J. Cytomegalovirus in hematopoietic stem cell transplant recipients: Current status, known challenges, and future strategies. Biol Blood Marrow Transplant. 2003;9(9):543-58.

123. Walter EA, Greenberg PD, Gilbert MJ, Finch RJ, Watanabe KS, Thomas ED, et al. Reconstitution of cellular immunity against cytomegalovirus in recipients of allogeneic bone marrow by transfer of T-cell clones from the donor. N Engl J Med. 1995; 333(16):1038-44.

124. van Esser JW, Niesters HG, van der HB, Meijer E, Osterhaus AD, Gratama JW, et al. Prevention of Epstein-Barr virus-lymphoproliferative disease by molecular monitoring and preemptive rituximab in high-risk patients after allogeneic stem cell transplantation. Blood. 2002;99(12):4364-9.

125. Hirsch HH, Steiger J. Polyomavirus BK. Lancet Infect Dis. 2003; 3(10):611-23.

126. Kharfan-Dabaja MA, Ayala E, Greene J, Rojiani A, Murtagh FR, Anasetti C. Two cases of progressive multifocal leukoencephalopathy after allogeneic hematopoietic cell transplantation and a review of the literature. Bone Marrow Transplant 2007; 39(2): $101-7$

127. Leung AY, Suen CK, Lie AK, Liang RH, Yuen KY, Kwong YL. Quantification of polyoma BK viruria in hemorrhagic cystitis complicating bone marrow transplantation. Blood. 2001; 98(6): 1971-8 
128. Erard V, Kim HW, Corey L, Limaye A, Huang ML, Myerson D, et al. BK DNA viral load in plasma: evidence for an association with hemorrhagic cystitis in allogeneic hematopoietic cell transplant recipients. Blood. 2005;106(3):1130-2.

129. Leung AY, Chan MT, Yuen KY, Cheng VC, Chan KH, Wong CL, et al. Ciprofloxacin decreased polyoma BK virus load in patients who underwent allogeneic hematopoietic stem cell transplantation. Clin Infect Dis. 2005;40(4):528-37.

130. Lau GK, He ML, Fong DY, Bartholomeusz A, Au WY, Lie AK, et al. Preemptive use of lamivudine reduces hepatitis B exacerbation after allogeneic hematopoietic cell transplantation. Hepatology. 2002;36(3):702-9.

131. La SB, Marrie TJ, Auffray JP, Raoult D. Mimivirus in pneumonia patients. Emerg Infect Dis. 2005;11(3):449-52.

132. Raoult D, Audic S, Robert C, Abergel C, Renesto P, Ogata H, et al. The 1.2-megabase genome sequence of Mimivirus. Science. 2004; 306(5700):1344-50.

133. Oliveira R, Machado A, Tateno A, Boas LV, Pannuti C, Machado C. Frequency of human metapneumovirus infection in hematopoietic SCT recipients during 3 consecutive years. Bone Marrow Transplant 2008;42(4):265-9.

134. Machado CM, Boas LS, Mendes AV, Santos MF, da R, I, Sturaro D, et al. Low mortality rates related to respiratory virus infections after bone marrow transplantation. Bone Marrow Transplant 2003;31(8):695-700.

135. de AE, Hayden FG, McAuliffe JF, de Sousa MA, Mota SB, McAuliffe MI, et al. Acute respiratory viral infections in ambulatory children of urban northeast Brazil. J Infect Dis. 1991; 164(2):252-8.

136. Machado CM, Boas LS, Mendes AV, da R, I, Sturaro D, Dulley FL, et al. Use of Oseltamivir to control influenza complications after bone marrow transplantation. Bone Marrow Transplant. 2004; 34(2):111-4.

137. Nichols WG, Guthrie KA, Corey L, Boeckh M. Influenza infections after hematopoietic stem cell transplantation: risk factors, mortality, and the effect of antiviral therapy. Clin Infect Dis. 2004;39(9):1300-6.

138. Ison MG. Adenovirus infections in transplant recipients. Clin Infect Dis. 2006;43(3):331-9.

139. Raad I, Abbas J, Whimbey E. Infection control of nosocomial respiratory viral disease in the immunocompromised host. Am J Med. 1997;102(3A):48-52.

140. Godoi ER, de S, V, Cakmak S, Machado AF, Vilas Boas LS, Machado $\mathrm{CM}$. Loss of hepatitis A virus antibodies after bone marrow transplantation. Bone Marrow Transplant. 2006;38 (1):37-40.

141. Engelhard D, Nagler A, Hardan I, Morag A, Aker M, Baciu H, et al. Antibody response to a two-dose regimen of influenza vaccine in allogeneic $\mathrm{T}$ cell-depleted and autologous BMT recipients. Bone Marrow Transplant. 1993;11(1):1-5.

142. Machado CM, de S, V, Sumita LM, da R, I, Dulley FL, Pannuti CS. Early measles vaccination in bone marrow transplant recipients. Bone Marrow Transplant. 2005;35(8):787-91.

143. Machado CM. Reimmunization after hematopoietic stem cell transplantation. Expert Rev Vaccines. 2005;4(2):219-28.

144. Manning SE, Rupprecht CE, Fishbein D, Hanlon CA, Lumlertdacha $\mathrm{B}$, Guerra $\mathrm{M}$, et al. Human rabies prevention--United States, 2008: recommendations of the Advisory Committee on Immunization Practices. MMWR Recomm Rep. 2008;57(RR3): $1-28$.

145. Anvisa - Agência Nacional de Vigilância Sanitária. Regulamento técnico para planejamento, programação, elaboração e avaliação de projetos fisicos de estabelecimentos assistenciais de saúde Resolução $\mathrm{n}^{\circ}$ 50. 2002.
146. Sehulster L, Chinn R, Arduino M, Carpente J, Dolan R, Ashford $\mathrm{D}$, et al. Guidelines for environmental infection control in healthcare facilities. Recommendations from CDC and the Health Infections Control Practices Advisory Committee (HICPAC). Chicago IL: 2004.

147. Anvisa - Agência Nacional de Vigilância Sanitária. Segurança do Paciente - Higienização das Mãos. 2008.

148. Pittet D, Allegranzi B, Boyce J. The World Health Organization Guidelines on Hand Hygiene in Health Care and their consensus recommendations. Infect Control Hosp Epidemiol. 2009;30 (7):611-22.

149. Ministério do Trabalho e Emprego. Norma Regulamentadora $\mathrm{n}^{\circ}$ 32 - Segurança e Saúde no Trabalho em Serviços de Saúde. 2005.

150. Marschall J, Mermel LA, Classen D, Arias KM, Podgorny K, Anderson DJ, et al. Strategies to prevent central line-associated bloodstream infections in acute care hospitals. Infect Control Hosp Epidemiol. 2008;29 Suppl 1:S22-S30.

151. OGrady NP, Alexander M, Dellinger EP, Gerberding JL, Heard SO, Maki DG, et al. Guidelines for the prevention of intravascular catheter-related infections. Centers for Disease Control and Prevention. MMWR Recomm Rep. 2002;51(RR-10):1-29.

152. Raad I, Hanna H, Maki D. Intravascular catheter-related infections: advances in diagnosis, prevention, and management. Lancet Infect Dis. 2007;7(10):645-57.

Este artigo foi avaliado pelos coordenadores das Diretrizes do Transplante de Medula Óssea da Sociedade Brasileira de Transplante de Medula Óssea, Luis Fernando Bouzas, Prof. Julio Cesar Voltarelli e Nelson Hamerschlak, e publicado após avaliação e revisão do editor, Milton Artur Ruiz.

Conflito de interesse: sem conflito de interesse

Recebido:19/10/2009

Aceito: 23/11/2009 